\title{
Conceptual Design Studies of Short Range Aircraft Configurations with Hybrid Electric Propulsion
}

\author{
Michael Iwanizki ${ }^{1}$ \\ German Aerospace Center, Braunschweig, 38108, Germany \\ Max J. Arzberger ${ }^{2}$ \\ German Aerospace Center, Oberpfaffenhofen, 82234, Germany \\ Martin Plohr ${ }^{3}$ \\ German Aerospace Center, Koeln, 51147, Germany \\ Daniel Silberhorn ${ }^{4}$ \\ German Aerospace Center, Hamburg, 21129, Germany \\ and \\ Tobias Hecken ${ }^{5}$ \\ German Aerospace Center, Goettingen, 37073, Germany
}

In this paper, the activities at the German Aerospace Center (DLR) related to the conceptual design studies of aircraft configurations with hybrid electric propulsion for a typical short range commercial transport mission in the scope of the European Clean Sky 2 program in the project "Advanced Engine and Aircraft Configurations" (ADEC) are described. The configurations analyzed incorporate different hybrid powertrain architectures consisting of gas turbines, electric machines, and batteries. Technologies as distributed propulsion are utilized for the boundary layer ingestion at the fuselage and for the powered yaw control. The synergetic effects of a canard configuration and a BLI propulsor at the rear of the fuselage are investigated. The focus of this paper is on the quantitative evaluation of configurations utilizing a conceptual aircraft sizing workflow built in the DLR's "Remote Component Environment" incorporating semi-empirical and low level physics based methods. In order to depict the rationale behind the investigated aircraft configurations, a brief overview of the foregone downselection process is given. The concepts evaluated in the scope of this work are shown. The multi-disciplinary overall aircraft sizing workflow is described. An overview of reference configurations is given. The design space studies of configurations with hybrid electric propulsion are presented. The most promising configurations are shown in detail and compared to the advanced reference aircraft. Finally, a conclusion is drawn and an outlook is presented.

\section{Nomenclature}

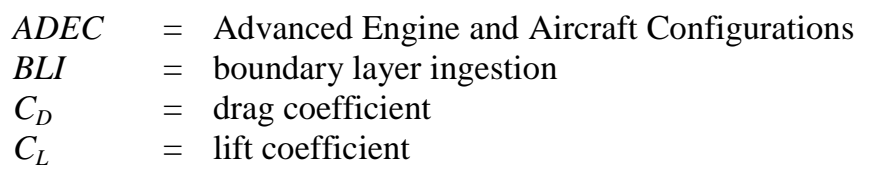

\footnotetext{
${ }^{1}$ Research engineer, Institute of Aerodynamics and Flow Technology, AIAA Member

${ }^{2}$ Research engineer, Institute of System Dynamics and Control

${ }^{3}$ Research engineer, Institute of Propulsion Technology

${ }^{4}$ Research engineer, Institute of System Architectures in Aeronautics

${ }^{5}$ Research engineer, Institute of Aeroelasticity
} 


$\begin{array}{ll}C_{M} & =\text { pitching moment coefficient } \\ C F R P & =\text { carbon fiber reinforced polymer } \\ C G & =\text { center of gravity } \\ D C & =\text { direct current } \\ D L R & =\text { German Aerospace Center } \\ D O H & =\text { degree of hybridization (power based) } \\ E I S & =\text { entry into service } \\ E T F & =\text { electrified turbofan } \\ G J & =\text { gigajoule } \\ H E P & =\text { hybrid electric propulsion } \\ H T P & =\text { horizontal tailplane } \\ L / D & =\text { lift to drag ratio } \\ m & =\text { meter } \\ M A C & =\text { mean aerodynamic chord } \\ M T O M & =\text { maximum take-off mass } \\ N L R & =\text { Netherlands Aerospace Centre } \\ N M & =\text { nautical mile } \\ O A D & =\text { overall aircraft design } \\ O E I & =\text { one engine inoperative } \\ O N E R A & =\text { French Aerospace Lab } \\ O E M & =\text { operating empty mass } \\ P_{b a t} & =\text { battery power } \\ P_{\text {gas } t u r b i n e} & =\text { power of the gas turbine } \\ P_{e l} & =\text { electric power } \\ P_{\text {max }} & =\text { maximum power } \\ P Y C & =\text { powered yaw control } \\ R C E & =\text { remote component environment } \\ S_{\text {ref }} & =\text { reference area } \\ t & =\text { metric ton } \\ T U & =\text { Technical University } \\ V T P & =\text { vertical tailplane } \\ & \end{array}$

\section{Introduction}

In this section the background information related to the conceptual aircraft design activities considering hybrid electric propulsion in the scope the project "Advanced Engine and Aircraft Configurations" (ADEC) in the framework of Clean Sky 2 at the German Aerospace Center (DLR) is summarized. The activities are dedicated to the challenging goals defined in the Flightpath 2050 [1] to reduce the environmental impact of transport aircraft.

\section{A. International Research Activities in the Field of Hybrid Electric Aircraft Configurations}

One approach to reduce the environmental impact of aircraft is to substitute the kerosene by other energy sources. The electrical energy offers a high potential due to the high efficiency of the electric machines. Also, electrical powertrains avail a high flexibility of distributing the propulsors in advantageous ways to further improve the performance of the aircraft. At the same time, full electric aircraft have strong limitation with respect to the transport capability due to a comparably low energy and power density of batteries [2]. Hybrid electric aircraft take advantages of the electric powertrains but avoid the severe mass impact of battery weight by only partially substituting the fuel by batteries and hence appear more promising according to the current research, as e.g. shown by Antcliff et al. [3]. Distributed propulsion that is enabled by electric powertrains is especially beneficial for small configurations, as described in [4]. Some benefits can be identified for regional aircraft according to Strack et al. in [5], and Antcliff and Capristan in [6]. The work of Welstead and Felder [7] shows promising results also for larger transport aircraft.

\section{B. Selection Process of Configurations in the Scope of Clean Sky 2, Project ADEC}

In the scope of the European Clean Sky 2 program, in the project ADEC, studies of hybrid electric configurations at conceptual design level are performed by the research entities in Germany (DLR), France (ONERA), and Netherlands (NOVAIR consortium consisting of TU Delft and NLR). As the starting point for the 
investigation of short aircraft configurations based on an AIRBUS A320, a set of promising concepts was proposed by those contributors during a collaborative workshop. The envisaged technology level was set to entry into service in 2035 (EIS2035). Utilizing those configurations, each team individually carried out a ranking based mainly on qualitative methods. Based on those results, different configurations were selected by the research entities for more profound analyses. In this paper, solely the subsequent activities at DLR are described. The work carried out by the NOVAIR consortium is published by Hoogreef et al. in [8], while the activities of the ONERA are summarized by Schmollgruber et al. in [9].

An overview of the downselection process at DLR within the project is given in Fig. 1. The general idea is to reduce the number of configurations and to increase the level of fidelity from phase to phase. The first downselection (phase 1) was carried out by qualitative methods incorporating the Phug's matrix [10] that was filled out based on expert judgement. In this step, the number of configurations was reduced from 35 to 12. For the next downselection (phase 2), overall aircraft design activities utilizing low level empirical and semi-empirical methods have been conducted. The number of hybrid electric configurations was reduced from 12 to 3 . In phase 3 , an overall aircraft design workflow that consists of combined semi-empirical and low-level physics based methods is utilized. This workflow is set up in the DLR's "Remote Component Environment" RCE [11] and enables fast and wide design studies at higher level of fidelity. This paper contains the results of the activities during the third phase.

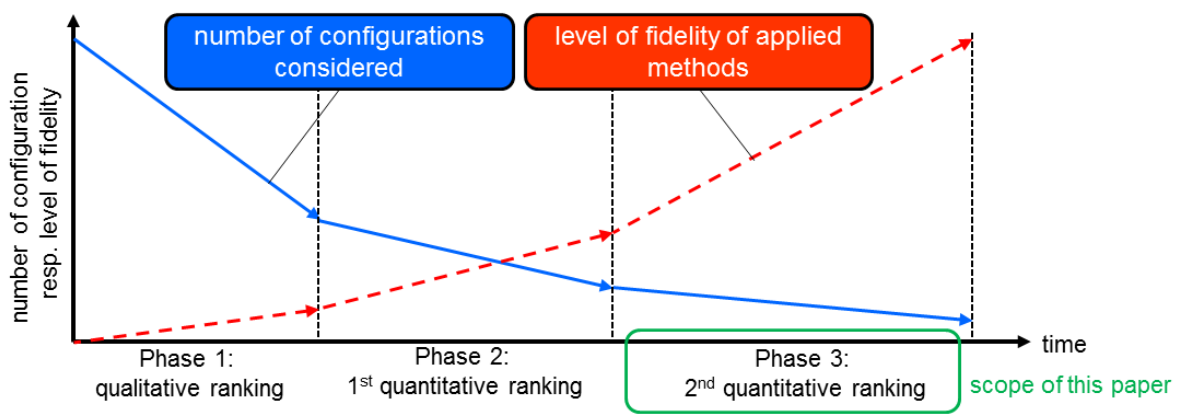

Fig. 1: Downselection process in the scope of the project ADEC at DLR

\section{Overall Aircraft Design of Hybrid Electric Configurations in this Paper}

Three hybrid electric concepts are analyzed in the scope of the studies presented in this paper. Furthermore, three reference configurations with conventional propulsion are included. An overview of all configurations is given in Fig. 2.

\begin{tabular}{|c|c|c|c|c|c|}
\hline \multicolumn{3}{|c|}{ Conventional propulsion system } & \multicolumn{3}{|c|}{ Hybrid electric propulsion system } \\
\hline & & & & & \\
\hline $\begin{array}{l}\text { Conventional reference } \\
\text { configuration (EIS1990) }\end{array}$ & $\begin{array}{l}\text { Advanced reference } \\
\text { configuration (EIS2035) } \\
\text { for } 2500 \text { NM }\end{array}$ & $\begin{array}{l}\text { Advanced reference } \\
\text { configuration (EIS2035) } \\
\text { for } 800 \text { NM }\end{array}$ & $\begin{array}{l}\text { "Boosted Turbofan" } \\
\text { configuration (EIS2035) }\end{array}$ & $\begin{array}{l}\text { "BLI-Canard" } \\
\text { configuration (EIS2035) }\end{array}$ & $\begin{array}{l}\text { "BLI-WingFan" } \\
\text { configuration (EIS2035) }\end{array}$ \\
\hline $\begin{array}{l}\text { Design mission: } \\
\text { - } \text { Range: } 2500 \mathrm{NM} \\
\text { - } \text { Payload: } 17 \mathrm{t} \\
\text { - } \text { Mach: } 0.78\end{array}$ & $\begin{array}{ll}\text { Design mission: } \\
\text { - } & \text { Range: } 2500 \mathrm{NM} \\
\text { - } & \text { Payload: } 17 \mathrm{t} \\
\text { - } & \text { Mach: } 0.78\end{array}$ & $\begin{array}{l}\text { Design mission: } \\
\text { - } \quad \text { Range: } 800 \mathrm{NM} \\
\text { - } \text { Payload: } 13.6 \mathrm{t} \\
\text { - } \text { Mach: } 0.78\end{array}$ & $\frac{\text { Technologies: }}{\text { - Parallel hybrid }}$ & $\begin{array}{l}\text { Technologies: } \\
\text { - Series/parallel partial } \\
\text { hybrid } \\
\text { - BLI-annular fan }\end{array}$ & $\begin{array}{l}\text { Technologies: } \\
\text { - Series/parallel partial } \\
\text { hybrid } \\
\text { - BLI-annular fan } \\
\text { - Fans at wing tips for } \\
\text { powered yaw control }\end{array}$ \\
\hline
\end{tabular}

Fig. 2: Overview of aircraft configurations considered

The conventional reference configuration represents a typical short range aircraft for entry into service in 1990. The first advanced reference configuration shows the impact of technologies for EIS2035. The second advanced reference shows the impact of the altered mission requirements, also considering technologies for EIS2035. The first hybrid electric configuration is the "Boosted Turbofan" concept that incorporates a parallel hybrid powertrain. The second configuration is the "BLI-canard" concept that is equipped with a series/parallel partial hybrid powertrain comprising an electrically driven boundary layer ingestion annular fan at the fuselage. The third configuration is the 
"BLI-WingFan" concept that is equipped with a series/parallel partial hybrid powertrain, an electrically driven boundary layer ingesting annular fan at the fuselage, and electrically driven fans at the wing tips for powered yaw control (PYC). For all hybrid electric configurations the power provided by batteries enables to relax the off-design requirements for the gas turbines making them more efficient at cruise conditions [12].

For the aircraft design studies the following approach is used: The conceptual sizing workflow is evaluated utilizing publically available data of a typical short range transport aircraft. In the second step, EIS2035 technologies are applied on this configuration and an optimization of the airframe is performed. This shows the impact of the assumed technologies at aircraft level without hybrid electric propulsion. Advanced airframe technologies that are not directly related to hybrid electric propulsion, as e.g. the hybrid laminar flow control, are not considered in these studies. Hence, this study outlines the impact of the hybrid electric powertrain. The third step is the adaption of the advanced reference configuration for the same top level aircraft requirements (TLARs) as the proposed hybrid electric configurations. This configuration serves as the benchmark for the majority of the hybrid electric concepts in the scope of this work. A detailed description of the reference configurations is given in section IV. For the hybrid electric configurations, design space explorations are performed to depict the impact of different parameters and to identify the most promising configurations (section $\mathrm{V}$ ). One major target is the utilization of a single process for the analyses of all configurations in order to ensure consistent results.

\section{Description of Sizing Workflow and Design Procedure}

The sizing process for the aircraft configurations investigated is implemented in the "Remote Component Environment" RCE [11] developed by DLR. It enables the coupling of disciplinary tools provided locally or by different institutes at different sites to a single process. The sizing workflow in RCE incorporates the Common Parametric Aircraft Configuration Schema "CPACS" [16,17] as the standard interface for the data exchange between the tools. In addition, python-based scripts are used for a generic data processing. Several optimizers, convergence loop drivers, and parameter study drivers are available in RCE by default.

The sizing workflow used for this work has been derived from the DLR projects ATLAs [18] and FrEACs [19] which proved the capabilities of this aircraft design process. In the scope of this project, this workflow is modified for the sizing of hybrid electric aircraft configurations. In particular, the sizing of the hybrid propulsion system and additional systems is performed in a specialized module which is added to the workflow. Several methods for the calculation of mass and aerodynamics have been adapted for the purpose of this work. Furthermore, modifications for the analysis of the canard configuration have been introduced.

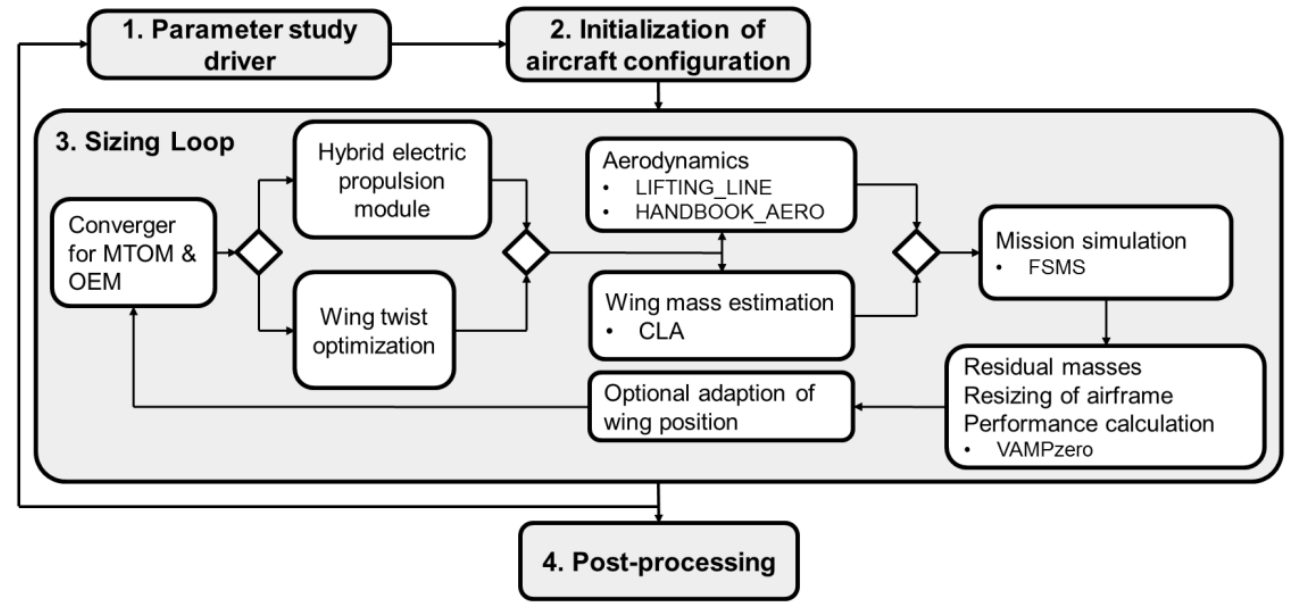

Fig. 3: Structure of workflow for sizing of hybrid electric aircraft

The structure of the aircraft sizing workflow is shown in Fig. 3. It consists of four general parts. First, the parameter study driver controls the top level design parameters. It allows performing automated parameter studies and optimization. In the second step, the general configuration of the aircraft is initialized based purely on empirical and semi-empirical methods. This configuration is iteratively processed in the third part ("sizing loop") of the workflow. It utilizes low level physics based methods for aerodynamics. The estimation of the wing mass is based on reduced order models derived from aero-elastic calculations as described in [20]. A 2D-mission simulation is used for the calculation of the fuel burn and electric energy demand. The sizing of the hybrid electric propulsion system considering the size of the fans, the gas turbines, the batteries, the electric motors, the conductors, the power 
electronics, and the cooling system is performed in the "hybrid electric propulsion" (HEP)-module. The twist of the wing is optimized during the sizing loop to achieve minimum induced drag. The remaining parameters are estimated by the DLR's overall aircraft design (OAD) tool VAMPzero [22]. This tool is based on semi-empirical or so-called handbook methods but is also able to utilize input data from higher fidelity analyses. For canard configurations, the location of the wing is adapted in a separate process in order to achieve the predefined static margin. After the initialization, the sizing loop iterates until the convergence of the maximum takeoff mass and the operating empty mass of the aircraft including the convergence of the sub processes is achieved. The fourth part is the post processing of the sized configuration. Detailed information about the individual modules and methods of the "sizing loop" are given in the sections below.

\section{A. Sizing of Hybrid Electric Powertrain and Calculation of Corresponding Masses}

The "hybrid electric propulsion" (HEP)-module performs the sizing of the main fans, gas turbines, additional fans, the battery, the electric power train components, and the cooling system according to the thrust requirements and the degree of hybridization (DOH). Subsequent to the sizing, it also performs a condensation of the different components composing the powertrain to generate an overall powertrain map. Furthermore, the HEP-module calculates the masses and the centers of gravity $(\mathrm{CG})$ of the corresponding components.

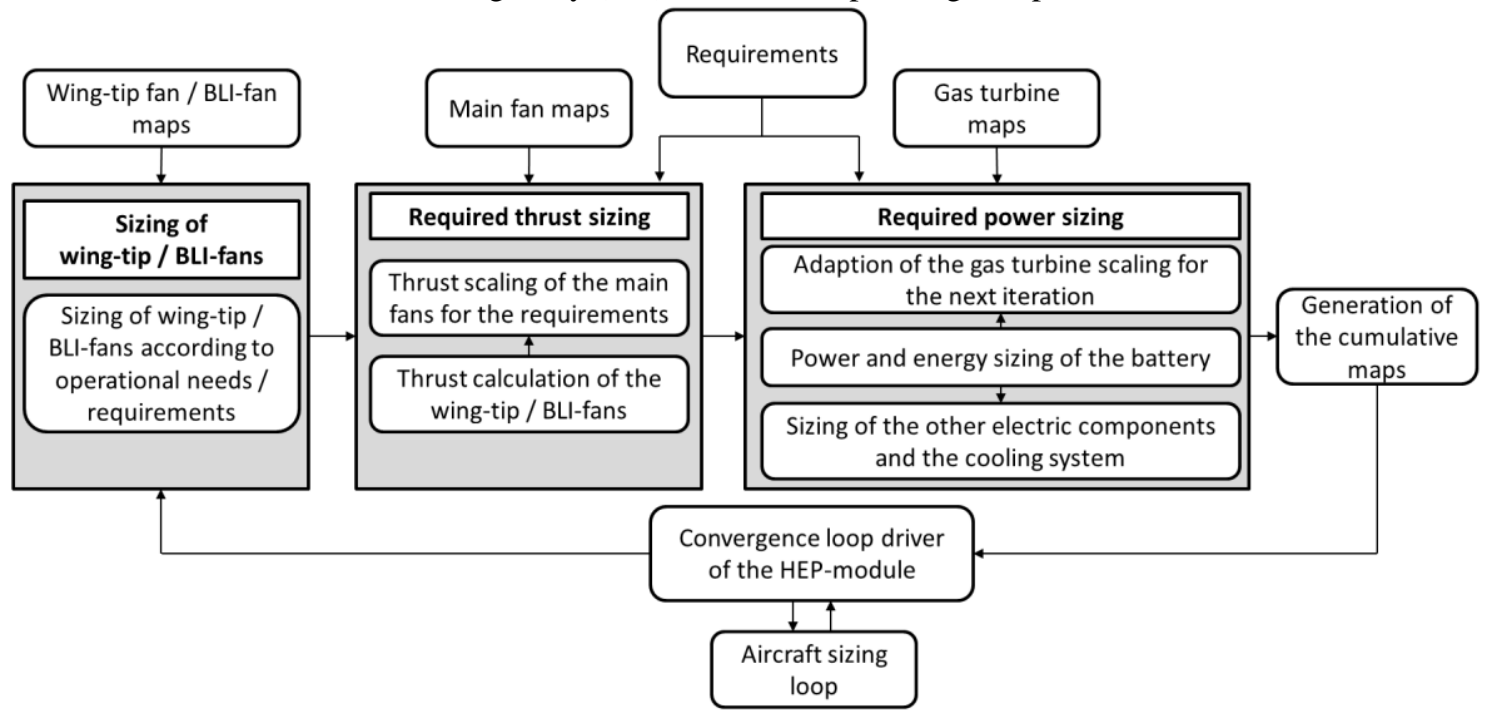

Fig. 4: Process of the "hybrid electric propulsion module"

\section{Description of sizing process for hybrid electric powertrain}

The sizing of the components is split into three main steps (Fig. 4). If the investigated configuration is equipped with tip fans for PYC or a BLI-fan, those are sized in the first step. Then, the main fans are dimensioned to provide the thrust for the typical requirements (take-off, second segment climb, and top of climb) considering the contribution of other propulsion units. Subsequent, the battery is sized to buffer the discrepancy between the power required by the propulsors and the power provided by the gas turbines assuming a fixed gas turbine scaling. After the power sizing of the battery, the power based degree of hybridization (DOH) is calculated as the maximum ratio of battery power and required total power in the critical power sizing point according to Eq.(1). To achieve the prescribed $\mathrm{DOH}$, an iterative process adapting the gas turbine scaling is required. This iteration also allows for the consideration of the gas turbine residual thrust during the sizing of the main fans. As convergence criteria, the absolute deviation from the degree of hybridization and the maximum delta of the gas turbines scale factor are utilized.

$$
D O H=\left(\frac{P_{b a t}}{P_{\text {gas turbines }}+P_{\text {bat }}}\right)
$$

The battery energy demand for the design mission is calculated based on the mission evaluation of the aircraft loop. Hence for the energy sizing of the battery, only mission data of the prior outer aircraft sizing iteration is available. Since the aircraft sizing loop is an iterative process, the convergence of the aircraft sizing loop also necessitates consistent HEP-module outputs. Thus, the convergence of the battery energy required for the design mission is guaranteed. 


\section{Thermodynamic modelling of engine components}

The fan and the gas turbines models are represented by thermodynamically calculated maps that contain power, thrust, spool speeds, fuel flow and other values as functions of altitude, Mach number, and thrust setting. For the sizing of the fans and the gas turbines, a linear scaling of the respective map is utilized. For different propulsors, individual maps that approximately comply with the thrust and the power requirements are provided.

3. Modelling of the boundary layer ingestion effects and scaling of the BLI fan

The impact of the boundary layer ingestion is captured by the "power saving coefficient" as defined by Smith [23] and is applied to a fan map which is calculated for free stream conditions. It is assumed that the whole boundary layer of the fuselage is ingested by the aft fan. In order to account for the losses due to the distorted inflow caused by a VTP in front of the BLI-fan, a reduction in efficiency of $1.5 \%$ is assumed. As the sizing point for the BLI-fan, the mid cruise condition is chosen.

4. Sizing of fans at the wing tips

The "BLI-WingFan" configurations use fans at the wing tips to provide PYC and to support the VTP in case on an engine failure. For this purpose the wing tip fan opposite to the failed main engine is propelled. The fraction of the total yaw torque for the second climb segment requirement is defined to scale the wing tip fans accordingly.

5. Sizing of the system components

The electric powertrain components are sized to transmit the maximum power required. Consequently, the respective sub-chains of electric components interconnecting at the central node, the flow direction, and the losses of the respective components are considered for the sizing. The cooling system is dimensioned such that it can cope with the electric losses apparent in the system during the different requirements and assumed to be distributed. The corresponding cooling drag is taken into account for the calculation of aerodynamics. The most general powertrain assumed is displayed in Fig. 5. It incorporates electrified turbofans (ETF) which combine a classic turbofan engine with an electric machine on the low pressure shaft, electric machines to drive additional fans, a battery providing the electric power for assisting the gas turbines during boost, power electronics for regulating the electric machines (and the battery), and cabling to interconnect the electric sub-chains in the central node. This layout is based on a DC distribution network.

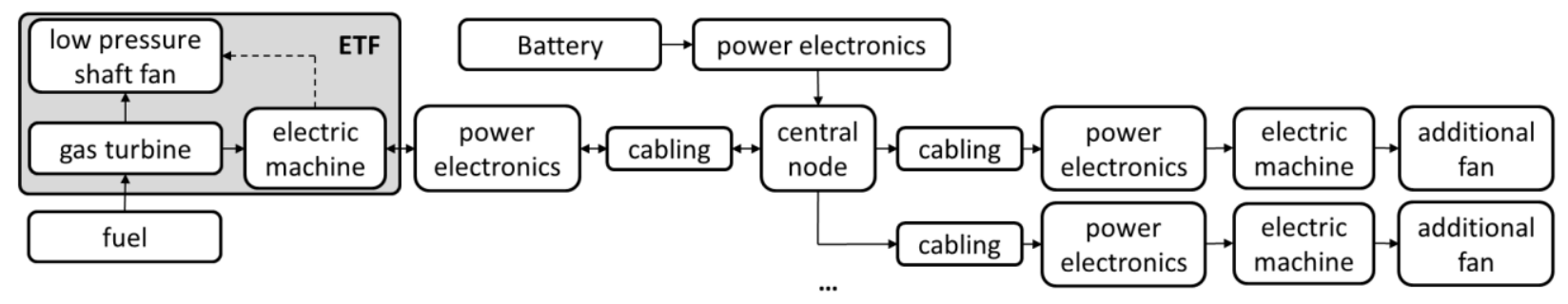

Fig. 5: General powertrain architecture

\section{Battery model}

The battery model is based on the same assumption for the battery power density and energy density as in [5]. In addition, a linear interdependency is applied in order to model the transition between power and energy cells as shown in Fig. 6. This approach is based on the evaluation of published battery data and constitutes a first order approximation of a Ragone plot. The battery is only considered in terms of mass. The corresponding volume is not taken into account during the sizing of the aircraft. The battery charge and discharge efficiency losses have been neglected.

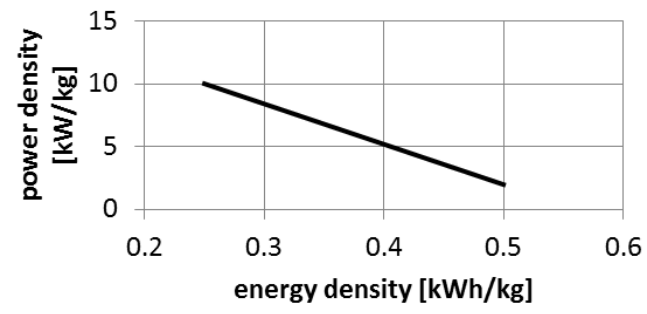

Fig. 6: Battery model

7. Approach for the generation of the combined engine map

After the sizing of the components, the overall map of the powertrain is generated. The BLI-fan is assumed to be the most efficient propulsion unit despite of the electric transmission losses. Hence, the BLI-fan is accelerated first 
while the main fans run at a fixed low thrust setting. As soon as the BLI-fan runs at the maximum constant power rating of the electric machine, this maximum rating is kept and the main fans are accelerated. The tip fans do not contribute to the thrust during a normal operation and are thus not directly considered in the cumulated power train map in terms of the available thrust. To provide the power for the propulsion units, first the gas turbines are driven to their maximum power in the respective operating condition. Then, the batteries start to buffer the power up to their maximum power rating. All of the fan operation points beyond the maximum available power are cut off.

\section{B. Disciplinary Methods in Aircraft Design Process}

In this section, the main method and tools used for the calculation of aerodynamics, masses besides the powertrain components, and mission parameters in the overall aircraft design loop are briefly described.

\section{Calculation of aerodynamics}

The drag polars are calculated for the whole operational envelope of the aircraft. The drag is decomposed in the induced drag, the viscous drag, the pressure drag, and the wave drag. For the calculation of the lift and the induced drag of the clean configuration the DLR's vortex lattice tool "LIFTING_LINE" [13] is used. The inputs for LIFTING_LINE are based on the geometry data stored in the CPACS input file. For the calculation of the viscous, the pressure, and the wave drag, the DLR's tool "HANDBOOK_AERO" is utilized. It incorporates several semiempirical methods for the estimation of component drag also based on the geometry data from the CPACS input file. The drag of the cooling system for the hybrid electric configurations is taken into account as well.

2. Mass estimation for components not included in the hybrid electric powertrain

The structural masses, the mass of the operational equipment, the furnishings, the systems that are not related to the hybrid electric powertrain, are calculated by different specialized tools. For the estimation of the wing mass the Concept Loads Analysis (CLA) tool is used. It is based on reduced order models from aero-elastic analyses for different wing configurations. Masses of the remaining components are calculated by the OAD-tool "VAMPzero" [22]. It is based on semi-empirical methods suitable of typical commercial transport aircraft configurations as for instance given by Raymer in [15] and Torenbeek in [21].

3. Mission simulation

The DLR's 2D mission simulation module FSMS ("Fast and Simple Mission Simulation") is utilized in the workflow to calculate the fuel consumption, the total energy demand, and the power levels required throughout the mission. The mission consists of the following segments: take-off, climb, cruise (assuming a continuous climb), descent, alternate mission, holding, and landing.

4. Calculation of remaining parameters

For those parameters that are not estimated by the aforementioned tools, the capabilities of the OAD-tool VAMPzero are exploited. As mentioned before, it is based on semi-empirical methods for the estimation of aerodynamics, masses, performance parameters etc. and can be used as a stand-alone conceptual aircraft design code. Taking into account the results from higher fidelity methods, VAMPzero is able to calculate the remaining parameters required for a consistent aircraft design.

\section{Description of Sizing Procedure and Assumptions}

In this section, the philosophy behind the sizing process including the major underlying assumptions is described. The utilized sizing workflow is essentially an analysis process for aircraft configurations that ensures consistent results. Parameter studies allow to investigate the design space and to identify the most promising configurations. Following parameters are used for all configurations: degree of hybridization, wing aspect ratio. Depending on the configuration, also the contribution of the fans at the wing tips, the length of the fuselage, the wing loading and the design range are varied. The sizing workflow automatically obtains the minimum thrust required for the given configuration based on the aerodynamics, masses and the propulsion system. Four critical operating points are used to identify the most critical thrust and power requirements. For all configurations the minimum thrust requirement is increased by $5 \%$ to improve the stability of automated studies. Since this value is applied for the HEP concepts and for the reference configurations, the relative deviation in performance is not affected.

The high lift performance is based on statistical values of existing aircraft. It is therefore prescribed by the designers. Essentially, the high lift performance and the wing loading of the conventional reference configuration are used. The impact of the aspect ratio on the high lift performance is neglected. For the canard configuration a parameter study is performed to depict the impact of a reduced wing loading.

The stability and control requirements are taken into account by tail volume coefficients based on statistical data. All configurations are designed for the same static margin in cruise conditions. For a lifting canard configuration, the location of the wing is adapted to comply with this requirement assuming an angle of incidence of the canard as 
suggested by Roskam in [24]. In cruise, this leads to a lift share of approximately $20 \%$ to $80 \%$ between the canard and the wing.

The BLI-fan is sized to balance the drag of the fuselage during the cruise condition. Thus this sizing point also defines the corresponding power requirement. This simplifying assumption limits the design space since it prescribes the sizing of the BLI-fan, and the mass of the related electric components.

For the fans at the wing tips it is assumed that they provide a prescribed fraction of the yaw moment to control the aircraft at take-off in the one engine inoperative (OEI) condition. The thrust required depends on the contribution fraction parameter and on the geometry of the aircraft. To adapt the VTP size accordingly, it is assumed that the force fraction contributed by the VTP is proportional to its volume coefficient. The dimensions of the VTP and the fans are calculated iteratively until the moment equilibrium is achieved.

For the evaluation and the comparison of configurations, the block fuel serves at the figure of merit. The block fuel is used because it is related to emissions that are directly produced by the aircraft during a regular mission.

\section{Description of Reference Configurations}

In this section, the reference configurations that serve as the benchmark for hybrid electric concepts in the scope of this work are presented. Two different missions are considered (Table 1). The conventional configuration is utilized to validate and to calibrate the sizing process. The first advanced reference configuration represents the benchmark for EIS2035 under consideration of the same design mission as the conventional reference (range: $2500 \mathrm{NM}$, payload: $17 \mathrm{t}$ ). The second advanced configuration is also sized with EIS2035 technologies but for a mission with a reduced range and payload (range: $800 \mathrm{NM}$, payload: $13.6 \mathrm{t}$ ). Both advanced configurations are equipped with a wing manufactured from a carbon fiber reinforced polymer (CFRP) and optimized for the $36 \mathrm{~m}$ wing box, according to the aerodrome reference code "C".

Table 1: Description of design missions

\begin{tabular}{lrrrrr}
\hline \hline Mission & \multicolumn{1}{l}{ Range } & Payload & Mach cruise & Alternate range & Loiter duration \\
\hline 1 & $2500 \mathrm{NM}$ & $17.0 \mathrm{t}$ & 0.78 & $200 \mathrm{NM}$ & $30 \mathrm{~min}$ \\
2 & $800 \mathrm{NM}$ & $13.6 \mathrm{t}$ & 0.78 & $200 \mathrm{NM}$ & $30 \mathrm{~min}$ \\
\hline \hline
\end{tabular}

\section{A. Conventional reference configuration}

As the conventional reference configuration the "CSR-01" form the publically accessible "Central Reference Aircraft Data System" CeRAS [14] provided by the Institute of Aerospace Systems (ILR) of the RWTH-Aachen University is used. It represents an AIRBUS-A320-like aircraft with the technology level for entry into service in 1990. The purpose of this model is the validation and the calibration of the sizing workflow. Furthermore, it serves as the reference for the field length performance, passenger capacity, and flight Mach number. Fig. 7 shows the geometry of the aircraft that is calculated by the workflow based on the top level aircraft requirements of the CSR01. In Table 2, the reference data of the calculated aircraft and the actual data of the CRS-01 are compared.

Table 2: Conventional reference configuration, comparison of results

\begin{tabular}{|c|c|c|c|c|}
\hline Parameter & Unit & $\begin{array}{l}\text { CeRAS } \\
\text { CSR-01 }\end{array}$ & $\begin{array}{l}\text { Conventional reference } \\
\text { configuration }\end{array}$ & Deviation \\
\hline MTOM & {$[\mathrm{t}]$} & 77.0 & 77.1 & $0.1 \%$ \\
\hline OEM & {$[\mathrm{t}]$} & 42.1 & 42.0 & $-0.2 \%$ \\
\hline wing area & {$\left[\mathrm{m}^{2}\right]$} & 122.4 & 122.5 & $0.1 \%$ \\
\hline wing aspect ratio & {$[-]$} & 9.5 & 9.5 & $0.0 \%$ \\
\hline mission fuel & {$[\mathrm{t}]$} & 18.18 & 18.06 & $-0.7 \%$ \\
\hline block fuel & {$[\mathrm{t}]$} & 14.79 & 14.24 & $-3.7 \%$ \\
\hline L/D cruise & {$[-]$} & 17.4 & 17.3 & $-0.7 \%$ \\
\hline
\end{tabular}

The configuration sized in RCE shows deviations below 1\% compared to the CeRAS CSR-01 database regarding the maximum take-off mass (MTOM), operating empty mass (OEM), wing area, aerodynamic performance in cruise (L/D), and mission loaded fuel mass. Regarding the block fuel, the deviation is about $4 \%$. A closer investigation revealed that the amount of the reserve fuel calculated by the sizing workflow is proportionally higher than the one 
of the CSR-01. Since the same sizing workflow is utilized for all configurations and the relative deviation in block fuel is the main parameter for the comparison of the configurations, this uncertainty has only a negligible impact on the final results.



Fig. 7: Geometry of conventional reference configuration

\section{B. Advanced reference configurations}

The advanced reference configurations in the scope of this work are based on a conventional airframe layout. They are equipped with turbofan engines at the technology level for entry into service in the year 2035. Since two different design missions are considered in the scope of this work (Table 1), for each mission a dedicated reference configuration is provided. Each reference configuration is sized under consideration of the same requirements and constraints as the HEP configurations. Hence, these configurations represent the potential benefit achievable by a conventional propulsion system combined with a conventional airframe. They serve as the benchmark for the HEP concepts.

1. Advanced Reference Configuration (EIS2035) for Design Range of 2500 NM and $17 t$ of Payload

For this configuration, the same design mission as for the conventional configuration is applied (Table 1, mission 1). The results show the impact of the technology assumptions for EIS2035. Fig. 8 illustrates the geometry of the aircraft. In Table 3, the corresponding data is summarized and a comparison to the conventional reference configuration from section $\mathrm{A}$ is included.

Table 3: Advanced reference configuration (EIS2035) for 2500NM and 17t of payload

\begin{tabular}{llrrr}
\hline \hline \multirow{2}{*}{ Parameter } & Unit $\begin{array}{l}\text { Conventional reference } \\
\text { configuration }\end{array}$ & \multicolumn{2}{l}{$\begin{array}{l}\text { Advanced reference } \\
\text { configuration for 2500NM }\end{array}$} & Deviation \\
\hline MTOM & {$[\mathrm{t}]$} & 77.1 & 72.5 & $-6.0 \%$ \\
OEM & {$[\mathrm{t}]$} & 42.0 & 41.8 & $-0.5 \%$ \\
wing reference area & {$\left[\mathrm{m}^{2}\right]$} & 122.5 & 115.2 & $-6.0 \%$ \\
wing aspect ratio & {$[-]$} & 9.5 & 11.3 & $18.7 \%$ \\
mission loaded fuel & {$[\mathrm{t}]$} & 18.06 & 13.65 & $-24.4 \%$ \\
block fuel & {$[\mathrm{t}]$} & 14.24 & 10.38 & $-27.1 \%$ \\
L/D cruise & {$[-]$} & 17.3 & 18.0 & $4.0 \%$ \\
\hline \hline
\end{tabular}

Table 3 contains the main parameters and the comparison of the advanced reference to the conventional reference. The reduced specific fuel consumption of the turbofan engine and the CFRP-wing along with a resized airframe lead to a significant reduction in the block fuel mass of $27 \%$. The MTOM is reduced by $6 \%$ which leads to 
a reduced reference area of the wing. This enables an increase in aspect ratio by $19 \%$ under consideration of the typical wing span constraint of $36 \mathrm{~m}$. Therefore, the aerodynamic performance in cruise conditions improves by $4 \%$.

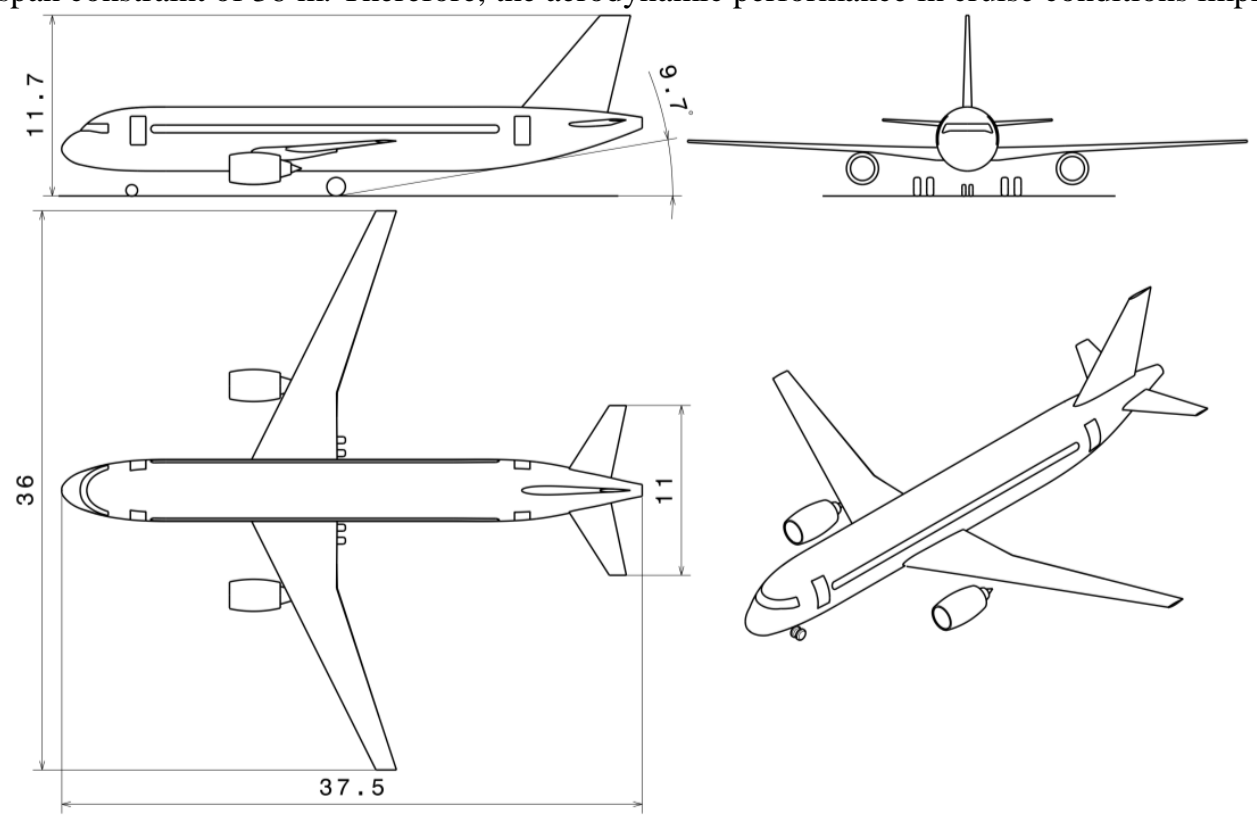

\section{Fig. 8: Geometry of Advanced Reference Configuration (EIS2035) for $2500 \mathrm{NM}$ and $17 \mathrm{t}$ of Payload}

In Fig. 8, it can be observed that the high aspect ratio combined with a constant taper ratio of the wing induces problems for the integration of the landing gear. It is assumed that the impact of this issue does not change the influence of the hybrid electric propulsion. Hence, this aspect is neglected in the scope of this work.

2. Advanced reference configuration (EIS2035) for design range of $800 \mathrm{NM}$ and 13.6 t of payload

The focus of the work in this paper is set to the mission with a design range of $800 \mathrm{NM}$ and a payload of $13.6 \mathrm{t}$ (Table 1, mission 2). The resulting geometry of the advanced reference configuration for this requirement is shown in Fig. 9. In Table 4, the corresponding aircraft data is summarized. In addition, a comparison is drawn to the advanced reference configuration that is designed for $2500 \mathrm{NM}$ and $17 \mathrm{t}$ of payload but operated at $800 \mathrm{NM}$ carrying 13.6 $\mathrm{t}$. This shows the impact of the resizing of the aircraft for the altered design mission.

Table 4: Advanced reference configuration (EIS2035) for 800NM and 13.6t of payload

\begin{tabular}{llllr}
\hline \hline & & $\begin{array}{l}\text { Advanced reference } \\
\text { configuration for 2500NM }\end{array}$ & \multicolumn{2}{l}{$\begin{array}{l}\text { Advanced reference } \\
\text { configuration designed } \\
\text { for 800NM }\end{array}$} \\
Parameter & Unit & & Deviation \\
\hline MTOM & {$[\mathrm{t}]$} & 72.5 & 61.1 & $-15.7 \%$ \\
OEM & {$[\mathrm{t}]$} & 41.8 & 38.6 & $-7.6 \%$ \\
wing reference area & {$\left[\mathrm{m}^{2}\right]$} & 115.2 & 97.1 & $-15.7 \%$ \\
wing aspect ratio & {$[-]$} & 11.3 & 13.3 & $18.6 \%$ \\
mission loaded fuel & {$[\mathrm{t}]$} & 6.34 & 5.45 & $-14.0 \%$ \\
block fuel & {$[\mathrm{t}]$} & 3.73 & 3.23 & $-13.5 \%$ \\
L/D cruise & {$[-]$} & 17.0 & 17.3 & $1.8 \%$ \\
\hline \hline
\end{tabular}

Due to the resizing of the aircraft, the block fuel required for the $800 \mathrm{NM}$ mission with a payload of $13.6 \mathrm{t}$ is reduced by $13.5 \%$. The wing aspect ratio is increased by $19 \%$ due to the lower take-off mass (16\%). This results in an improved lift-to-drag ratio of $2 \%$. Similar to the advanced reference configuration for $2500 \mathrm{NM}$, a problem regarding the integration of the landing gear is observed (Fig. 9). The inner section of the high aspect ratio wing is upfront the main landing gear that is positioned according to the center of gravity requirements. In addition, the sizing of the empennage with constant tail volume coefficients results in a comparably small horizontal tailplane due to the short mean aerodynamic chord (MAC) of the wing and the small reference area. It is assumed, that these 
issues do not affect the influence of the hybrid electric propulsion notably when compared to conventional reference configurations. Therefore, these aspects are neglected in the scope of this work.

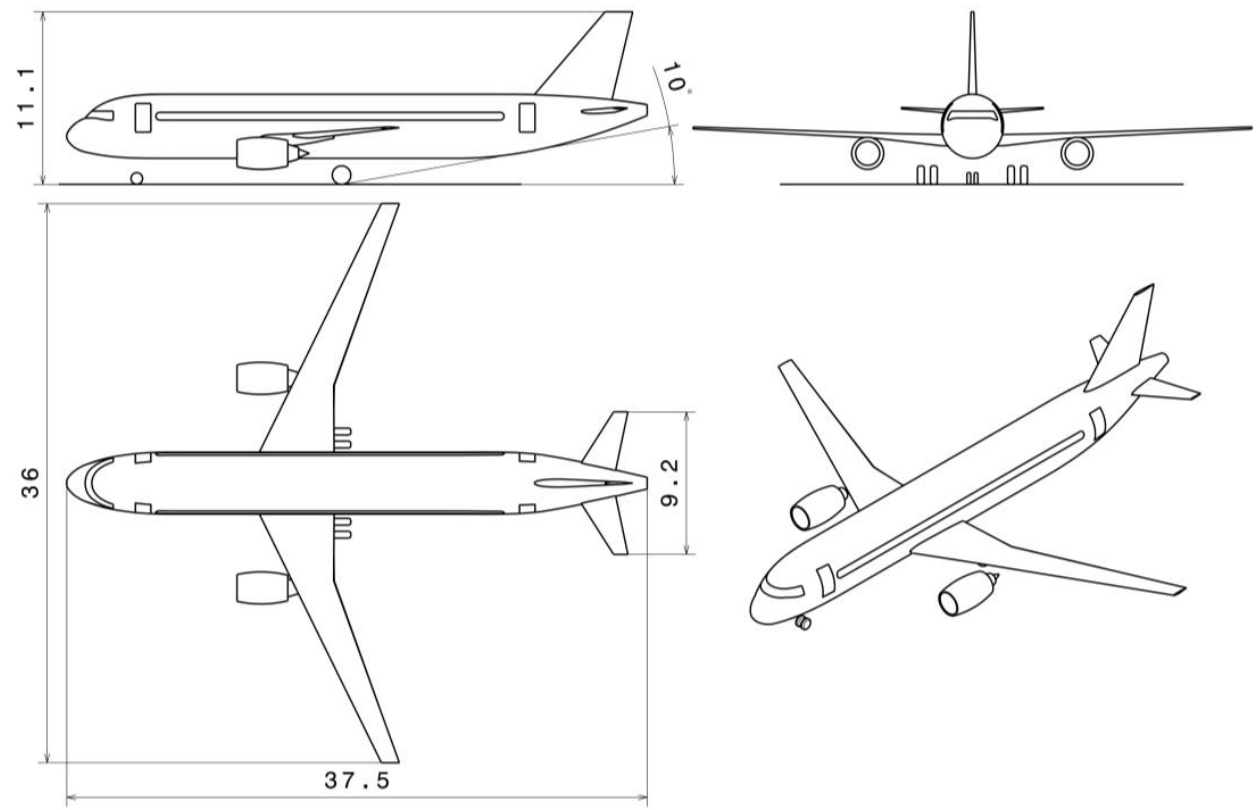

Fig. 9: Geometry of Advanced Reference Configuration (EIS2035) for $800 \mathrm{NM}$ and $13.6 \mathrm{t}$ of payload

\section{Parameter Studies to Identify Most Promising HEP Configurations}

In this section, the derivation of the investigated hybrid electric configurations is described. For each configuration, a brief overview of the concept is given, the design space exploration is shown, the most promising result is depicted, and the comparison to the advanced conventional configuration for the corresponding design mission is drawn. Finally, all configurations are compared and the results are discussed.

\section{A. Parameter Studies Related to "Boosted Turbofan" Configuration}

For the "Boosted Turbofan" configuration, studies regarding the degree of hybridization, the wing aspect ratio, and the design mission are carried out. Both design missions are described in Table 1.

1. Description of "Boosted Turbofan" configuration

The "Boosted Turbofan" configuration incorporates a parallel hybrid powertrain (Fig. 10) with an ETF and electric energy stored in batteries. The electric engines at the ETFs mainly serve for assisting the gas turbines in offdesign regions. For this configuration, an architecture with a direct feeding battery is assumed since the electric power network is entirely regulated by the inverter of the electric machine for boosting the turbofan. This powertrain enables a more flexible sizing of gas turbines increasing their efficiency in cruise conditions. Also, electrical energy can substitute fuel. The airframe itself is not notably changed by the hybrid electric system on this configuration. Thus, this step towards the hybridization of aircraft bares the lowest risk. Also, the fidelity level of results related to aerodynamics and masses is considered at the same reliable level as for the conventional configurations.



Fig. 10: Power flow of parallel hybrid powertrain ("boosted turbofan")

2. Design space exploration, "Boosted Turbofan" configuration for $800 \mathrm{NM}$ and 13.6 t of payload

To identify the most promising boosted turbofan configuration for the range of $800 \mathrm{NM}$ and a payload of $13.6 \mathrm{t}$, the design space is investigated w.r.t. the degree of hybridization and the wing aspect ratio. A typical wing box constraint of $36 \mathrm{~m}$ is applied. In Fig. 11, the relative deviations of the block fuel, the block energy, and the MTOM 
compared to the advanced reference configuration are shown. The wing span constraint of $36 \mathrm{~m}$ is marked by the red line. The valid design space is to the left from this line. The step sizes for the calculations are 0.1 for the DOH and 1.0 for the aspect ratio. The grid intersections highlight the calculated values. Between those points, the results are interpolated.

The study shows a small region where the "Boosted Turbofan" configuration exhibits a benefit of $2 \%$ in terms of the block fuel mass. For the block energy, the number is slightly reduced. Regarding the MTOM, no reduction can be identified in the whole design space. The relaxation of the wing span constraint would increase the benefit for both, the HEP configurations and the conventional configurations that are represented by the DOH of 0.0. The potential benefit does not notably change for higher aspect ratios.
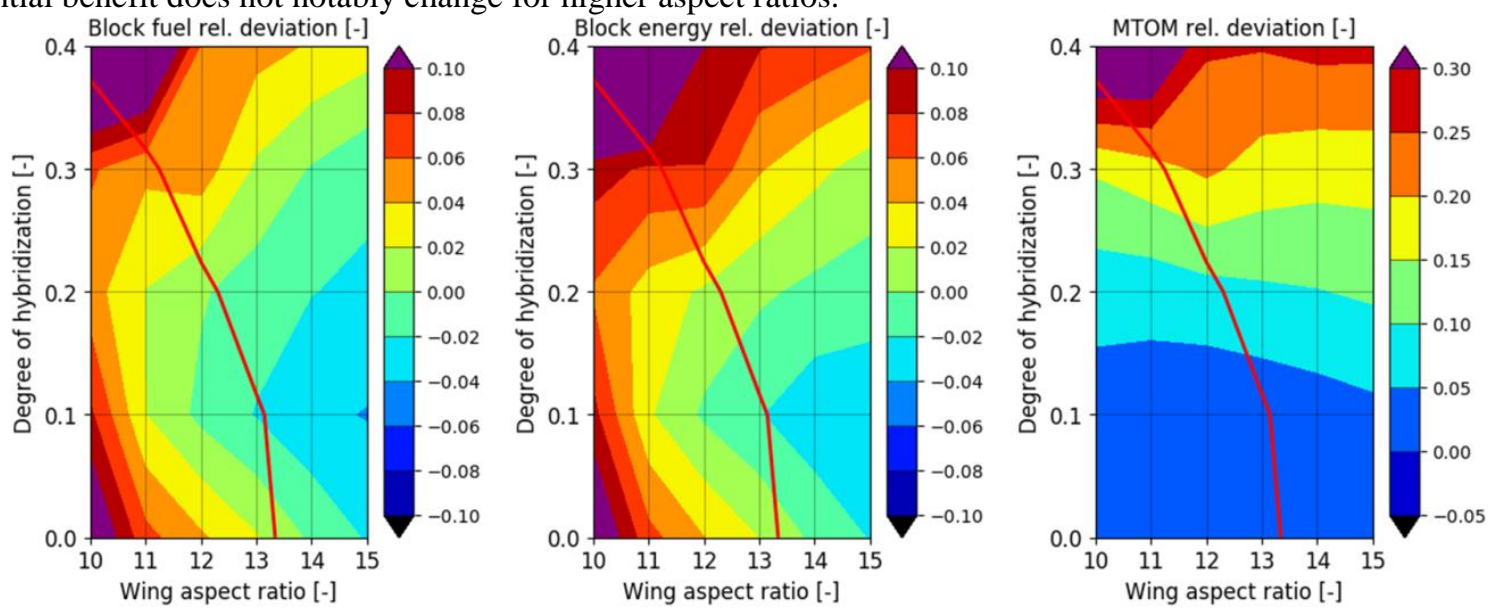

Fig. 11: Relative deviation in block fuel, block energy, and MTOM to the advanced reference configuration (design range: $800 \mathrm{NM}$, payload $13.6 \mathrm{t}$ )

\section{Description of most promising "Boosted Turbofan" concept for $800 \mathrm{NM}$ and 13.6 t of payload}

Based on the design space exploration, the most promising "Boosted Turbofan" configuration with respect to the block fuel is identified. The geometry of the aircraft is shown in Fig. 12. Table 5 contains the key parameters and the comparison to the advanced reference configuration with the identical design mission.

Table 5: Boosted turbofan configuration, key parameters

\begin{tabular}{llrrr}
\hline \hline \multirow{2}{*}{ Parameter } & \multicolumn{2}{c}{ Advanced reference } & \multicolumn{2}{c}{ Boosted Turbofan } \\
Unit & configuration for 800NM & for 800NM & Deviation \\
\hline MTOM & {$[\mathrm{t}]$} & 61.1 & 61.9 & $1.4 \%$ \\
OEM & {$[\mathrm{t}]$} & 38.6 & 39.6 & $2.6 \%$ \\
wing reference area & {$\left[\mathrm{m}^{2}\right]$} & 97.1 & 98.4 & $1.4 \%$ \\
wing aspect ratio & {$[-]$} & 13.3 & 13.0 & $-2.5 \%$ \\
block fuel & {$[\mathrm{t}]$} & 3.23 & 3.16 & $-2.1 \%$ \\
block energy & {$[\mathrm{GJ}]$} & 138.6 & 136.0 & $-1.9 \%$ \\
battery mass & {$[\mathrm{t}]$} & 0.0 & 0.6 & - \\
electric propulsion system & {$[\mathrm{t}]$} & 0.0 & 0.7 & - \\
cooling system & {$[\mathrm{t}]$} & 0.0 & 0.1 & - \\
L/D cruise & {$[-]$} & 17.3 & 17.4 & $0.4 \%$ \\
\hline \hline
\end{tabular}

The most promising degree of hybridization appears at $10 \%$. The MTOM is increased by $1 \%$ compared to the reference configuration. The additional mass of the electric propulsion system, the cooling system, and the battery is about $1.4 \mathrm{t}$. The higher mass and the constant wing loading assumed for the calculations result in a reduced wing aspect ratio of $2 \%$. The L/D-ratio in cruise conditions remains approximately unchanged. The block fuel mass and the block energy are reduced by $2.1 \%$ compared to the advanced reference configuration. 

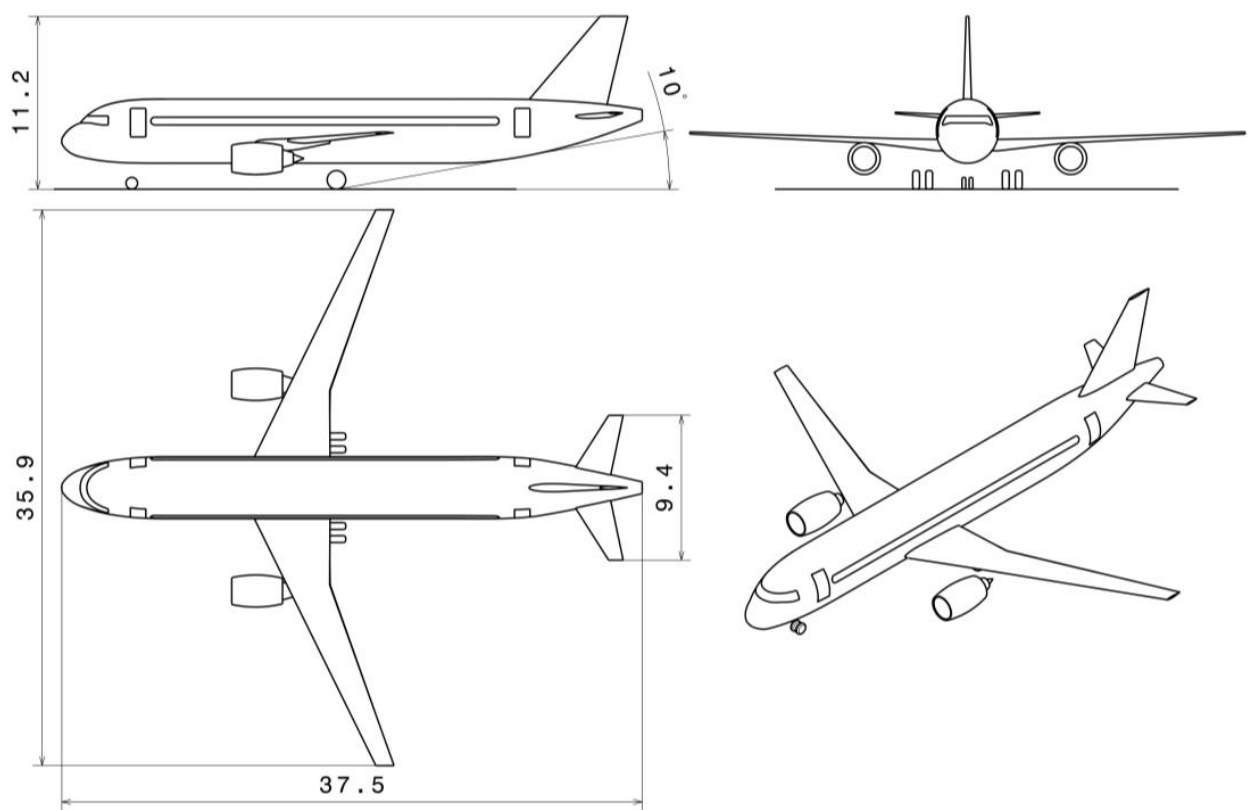

Fig. 12: Geometry of "Boosted Turbofan" configuration ( $800 \mathrm{NM}, 13.6 \mathrm{t}$ of payload)

\section{Design space exploration, "Boosted Turbofan" configuration for 2500 NM and 17 t of payload}

A design space survey is performed to evaluate the potential of the boosted turbofan configuration at the design range of $2500 \mathrm{NM}$ considering the payload of $17 \mathrm{t}$. In Fig. 13, the relative deviations in block fuel, block energy, and MTOM to the advanced reference for $2500 \mathrm{NM}$ are shown. The wing span constraint of $36 \mathrm{~m}$ is marked by the red line. The maximum benefit in fuel consumption and energy demand is approximately $2.5 \%$. The most beneficial DOH is $10 \%$. The deviation in MTOM is about $1 \%$.
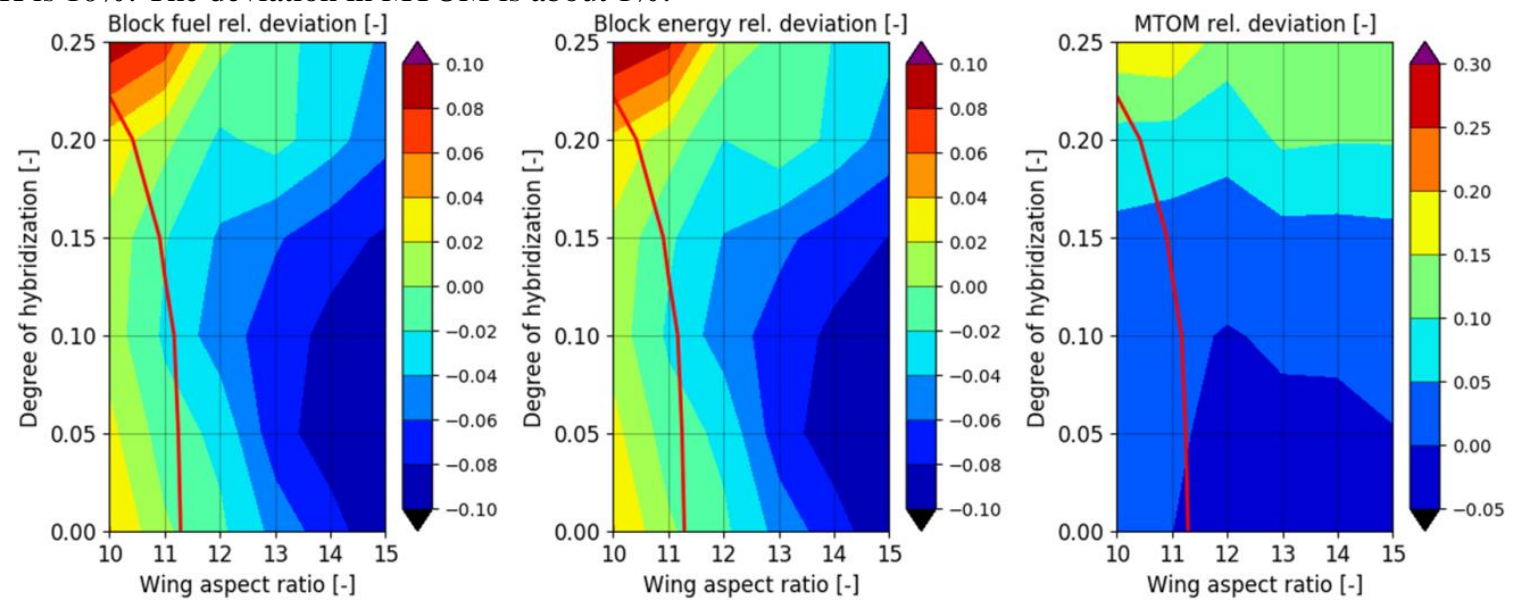

Fig. 13: Relative deviation in block fuel, block energy and MTOM for "Boosted Turbofan" configurations (design range: $2500 \mathrm{NM}$, payload $17 \mathrm{t}$ )

\section{B. Parameter Studies Related to the BLI-Canard Configuration}

For the "BLI- Canard" configuration, studies regarding the degree of hybridization, wing aspect ratio, and the length of the fuselage are carried out. In addition, a sensitivity study related to the high lift performance is performed.

1. Description of "BLI-Canard" configuration

The "BLI-Canard" configuration incorporates a powertrain as shown in Fig. 14 that combines the boosted turbofan and the turboelectric concept. It corresponds to the series/parallel partial hybrid architecture according to NASA's nomenclature. The electric engines at the ETF mainly serve as generators to provide the power for the BLIfan. In off-design regions, the battery serves as additional power source and assists the gas turbines. To allow for a 
better coordination of the power feed by the generators and the battery during this boosted operation, the battery is connected to the central node via power electronics. Theoretically, also an operation of the electric machines at the ETF is admissible. This powertrain enables a higher efficiency of gas turbines at cruise conditions and the utilization of an efficient boundary layer ingesting fan at the fuselage. The rationale behind the combination of this powertrain with a canard-airframe is the simplified integration of the aft-fan nacelle at the fuselage due to the absence of tailplanes. The inflow of the BLI-propulsor is less disturbed than in case of a rear mounted empennage. There is also the potential to reduce the length of the fuselage due to the aft fan preventing flow separation at a steep tailcone [15].

The additional propulsion system at the rear end of the fuselage induces a rearward shift of the center of gravity. This leads to a backward shift of the wing. While the shift is disadvantageous for a configuration with rear mounted stabilizers due to a reduced length of the lever arms, for a canard configuration the lever arm of the HTP is actually increased. The yaw moment caused by the failure of one of the engines for this configuration is smaller compared to a twin-engine configuration. In this case the BLI-fan runs at half of its power and provides a portion of the total thrust in the symmetry plane thus reducing the thrust that is required form the remaining wing engine. This enables a reduction in size of the vertical stabilizers. At the same time, due to the location of the VTPs at the wing tips, the lever arm is reduced. This leads to an increase in size of the VTPs counteracting the aforementioned beneficial effect.

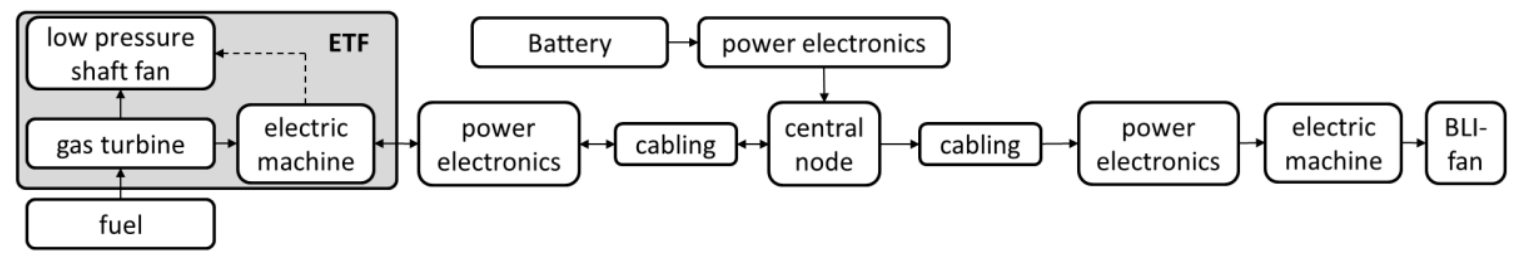

Fig. 14: Power flow of series/parallel partial hybrid powertrain for BLI-Canard configuration

The unconventional layout of the canard configuration challenges the application of semi-empirical methods. Through the utilization of the vortex lattice method for the lift, induced drag, pitching moment, and the component based estimation of viscous drag, pressure drag, and wave drag, reliable aerodynamic data is expected. For the mass estimation in the sizing workflow, the uncertainty is higher, since this discipline is covered mainly by semiempirical methods that are not adapted for canard configurations.

The disadvantages of the general layout of a canard configuration in terms of aerodynamics, as well as stability and control [15] reduce the potential performance gains of this concept. Nevertheless, synergetic effects of the BLIfan at the fuselage combined with this airframe remain promising as discussed before.

2. Configurational impact of "Canard" configuration

A "Canard" configuration is the baseline airframe layout for the "BLI- Canard" concepts. Therefore, a canard configuration that is equipped with a conventional propulsion system (without HEP) is analyzed in order to outline solely the impact of the configurational changes. For this purpose a design space survey is performed and the most promising canard configuration is compared to the advanced reference configuration in Fig. 15. According to the results, the aerodynamic performance of the aircraft is decreased by $2.5 \%$ and the mass is increased by $1 \%$ leading to an increase in block fuel mass of 3.8\%. It is assumed that an improved performance can be achieved by a more sophisticated optimization of this configuration. In the scope of these studies the calculated value is used without modifications.



Fig. 15: Configurational impact of the canard configuration

\section{Design space exploration, BLI-Canard configuration for $800 \mathrm{NM}$ and $13.6 \mathrm{t}$ of payload}

For the BLI-Canard configuration, the degree of hybridization, the wing aspect ratio, and the fuselage length are considered as parameters. It is assumed that a similar high lift performance as for the reference configuration can be achieved by utilizing a more complex high lift system at the canard and the wing. Hence, the same wing loading, related only to the area of the main wing, as for the reference configuration is applied. A sensitivity study related to the decay in the high lift performance is conducted in order to evaluate the impact of this assumption. 
In Fig. 16, the relative deviation of block fuel mass compared to the advanced reference configuration depending on the degree of hybridization, the wing aspect ratio, and the length of the fuselage is illustrated. In the graphs below, the lengths of the fuselages are $100 \%$ that corresponds to $37.5 \mathrm{~m}, 97.3 \%$ (reduction by $1 \mathrm{~m}$ ), and $94.7 \%$ (reduction by $2 \mathrm{~m}$ ). The wing span constraint of $36 \mathrm{~m}$ is marked by the red line. The valid design space is to the left of it. The configurations with DOH of 0 represent an exclusive BLI utilization without boosting by battery.
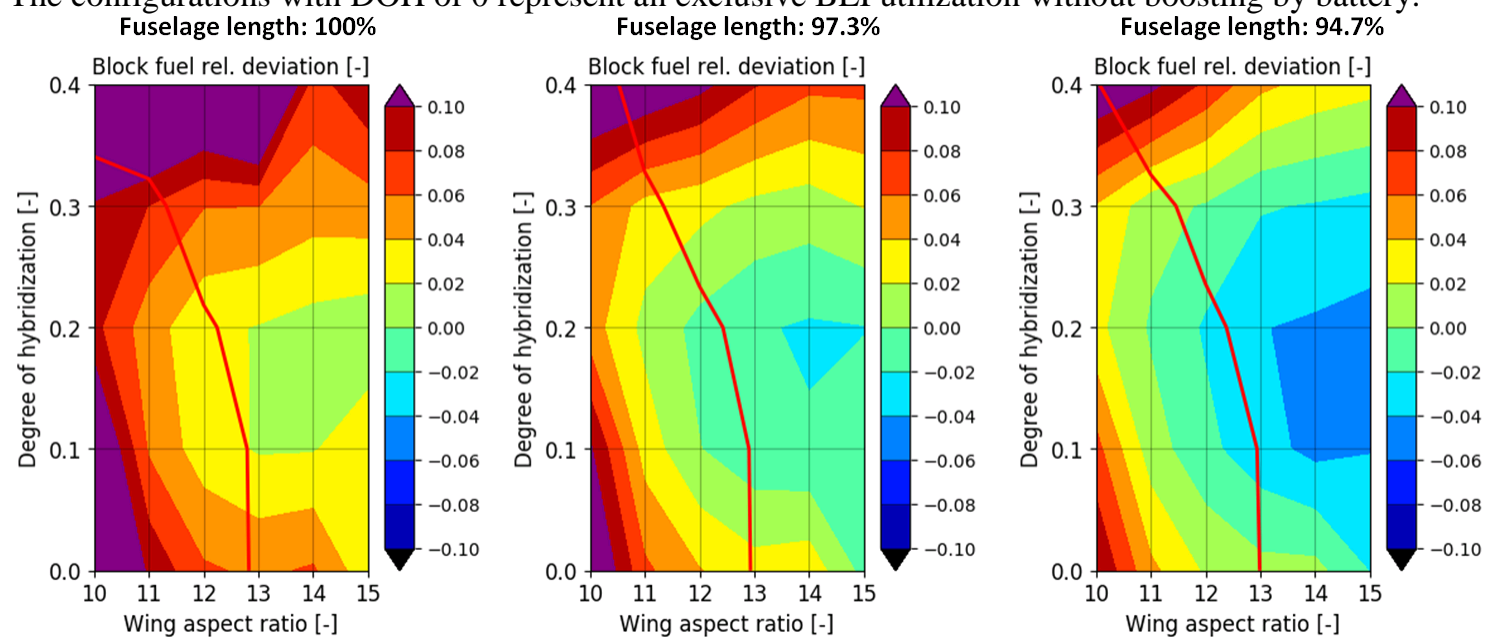

Fig. 16: Relative deviation in block fuel mass depending on the degree of hybridization, wing aspect ratio, and the length of the fuselage (design range: $800 \mathrm{NM}$, payload $13.6 \mathrm{t}$ )

As expected, the decrease of the fuselage length improves the performance of the canard configuration. It is to be noted that for these studies the reduced length of the fuselage impacts the aerodynamics but not the mass. This assumption is made because only the length of the partially unpressurized tail cone section is modified.

From the graphs, no benefit in block fuel mass is observed for the configurations with the unchanged fuselage length within the $36 \mathrm{~m}$ wing box. Through the reduction of the fuselage length by $2.7 \%(1 \mathrm{~m})$ the block fuel can be reduced by up to $1 \%$. A reduction by $5.3 \%(2 \mathrm{~m})$ allows a block fuel saving of about $3 \%$ compared to the advanced reference for the identical design mission.

4. Description of most promising "BLI-Canard" concept for $800 \mathrm{NM}$ and $13.6 \mathrm{t}$ of payload

The most promising "BLI-Canard" configuration is identified based on the design space exploration. Regarding the length of the fuselage, a reduction by about $5 \%(2 \mathrm{~m})$ is assumed. This value is based on the root chord length of the HTP which would be located in this tail segment in case of a conventional layout. Nevertheless, this assumption is comparably rough and should be evaluated in detail considering all the disciplines involved in the fuselage design and the BLI-engine design process in future.

The best set of parameters manifests at $\mathrm{DOH}$ of $10 \%$ and wing aspect ratio of 13 . This leads to a negligible violation of the wing span constraint by less than $1 \%$. The geometry of the aircraft is shown in Fig. 17. In Table 6 , the key parameters and the comparison to the advanced reference configuration are displayed.

Compared to the advanced reference configuration, the BLI-Canard concept exhibits a 3.3\% lower block fuel mass, and a similar impact on block energy. The MTOM is increased by $3 \%$. The L/D-ratio is improved by $2 \%$. A significant disadvantage of the "BLI-Canard" is the size of the VTPs as shown in Fig. 17. Since they are located at the wing tips, the lever arm is reduced compared to a fuselage mounted configuration. The purpose of this layout is a reduced inflow distortion for the BLI-fan. But this advantage is diminished by the increased area of the vertical stabilizers. Also, the chord length of the winglets that act as VTPs is significantly higher than the chord length at the the wing tip. Consequently, the structural complexity is increased. An optimization of the wing planform could reduce the impact of those drawbacks, but is out of the scope of this paper. Furthermore, due to the current position of the canard, the front access door has to be relocated. The position of the rear access doors has to be revised also. Therefore, a redesign of the cabin is required. 
Table 6: "BLI-Canard" configuration, key parameters

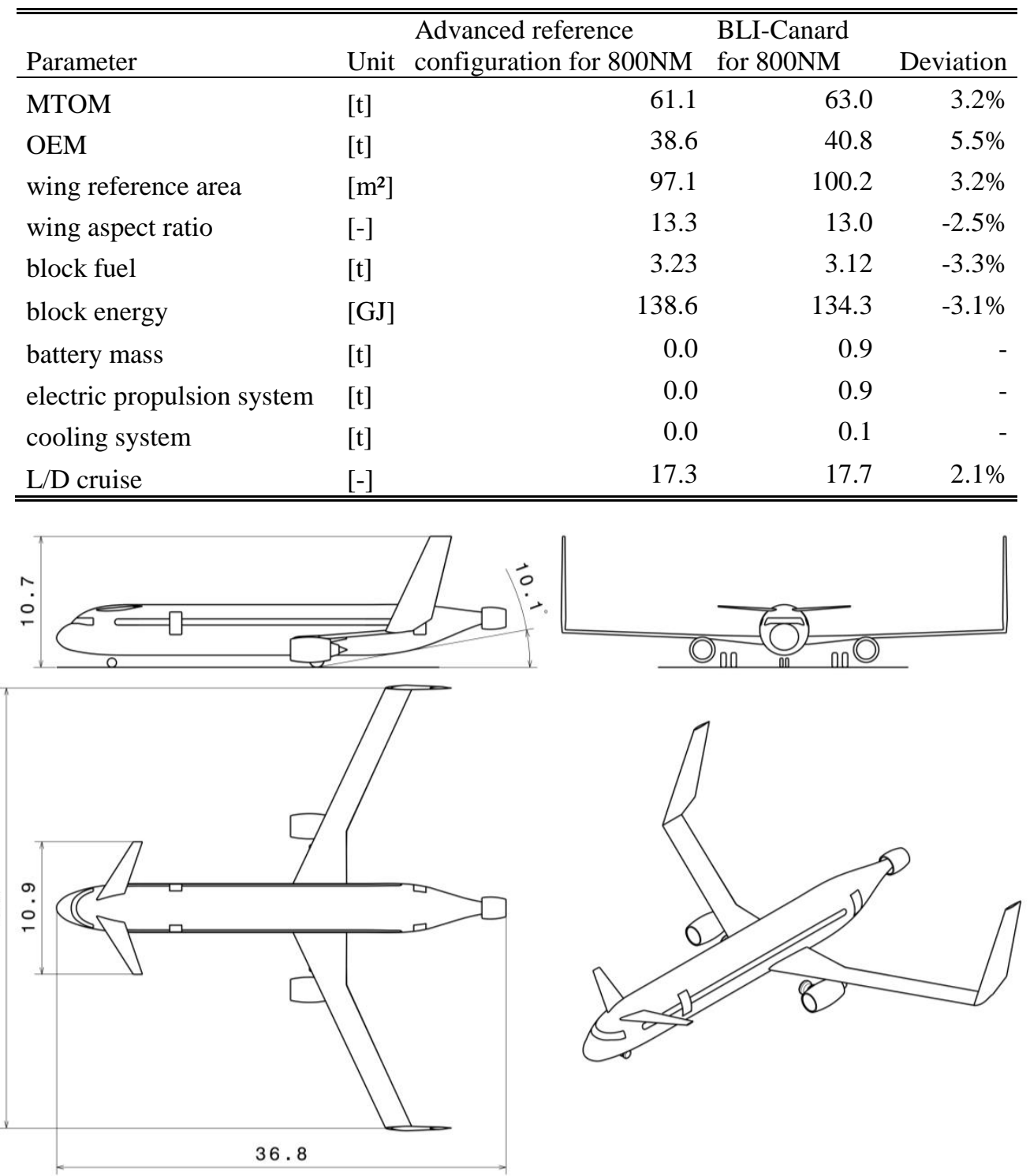

Fig. 17: Geometry of "BLI-Canard" configuration (800 NM, $13.6 \mathrm{t}$ of payload)

\section{Parameter studies related to the high lift performance}

As described in [15], a canard configuration suffers from deterioration in high lift performance. In the following studies the impact of the reduced high lift performance on the block fuel at aircraft level is investigated. In Fig. 18, the results are compared to the most promising "BLI-Canard" configuration described before.
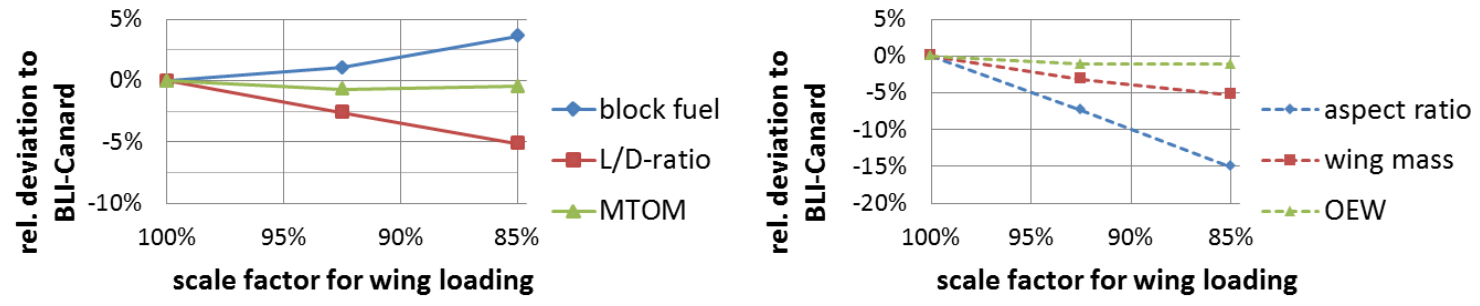

Fig. 18: Impact of reduced wing loading on BLI-canard configuration 
Three cases are compared: high lift performance as for the reference configuration, high lift performance reduced by $7.5 \%$, and high lift performance reduced by $15 \%$. In order to comply with the field length requirements, the wing loading is adapted accordingly. All studies are performed with the optimistic fuselage length of $35.5 \mathrm{~m}$ under consideration of the wing span constraint of $36 \mathrm{~m}$.

The reduced high lift performance and the accordingly increased wing reference area decrease the achievable wing aspect ratio under consideration of the wing span constraint of $36 \mathrm{~m}$ leading to a reduced L/D-ratio. The MTOM and OEM remain nearly constant mainly due to the reduced wing mass. The reduction of the wing loading by $7.5 \%$ leads to an increase in block fuel mass by $1 \%$. A further reduction of $15 \%$ leads to an increase of $3 \%$. The latter case would compensate the whole benefit obtained by the integration of the proposed hybrid electric powertrain.

\section{Parameter Studies Related to the "BLI-WingFan" Configuration}

For the "BLI-WingFan" configuration, studies regarding the degree of hybridization, wing aspect ratio, and the contribution of the fans at the wing tips to the yaw control are carried out. Due to the results, two different configurations are described in detail.

1. Description of "BLI-WingFan" configuration

The "BLI-WingFan" configuration incorporates a tube-and-wing airframe layout with a T-tail, a BLI-fan at the fuselage, and propulsors at the wing tips to enable powered yaw control and to reduce the size of the VTP. Potentially, the bypass ratio could also be increased for this configuration by the utilization of the tip fans in cruise. However, it is out of the scope of this paper. On the other hand, additional masses and additional drag due to the nacelles are expected. The powertrain in Fig. 19 is a combination of a parallel hybrid and a turbo-electric powertrain. It mainly coincides with the powertrain of the "BLI-Canard". However, the battery and electric machines at the ETF also have to supply additional power to the wing tip fans during OEI. Thus, it allows supporting the gas turbines at off-design conditions through the electric power from batteries improving their efficiency at cruise conditions. Furthermore, it utilizes a BLI-propulsor to improve the propulsive efficiency. This powertrain corresponds to the series/parallel partial hybrid architecture according to NASA's nomenclature.
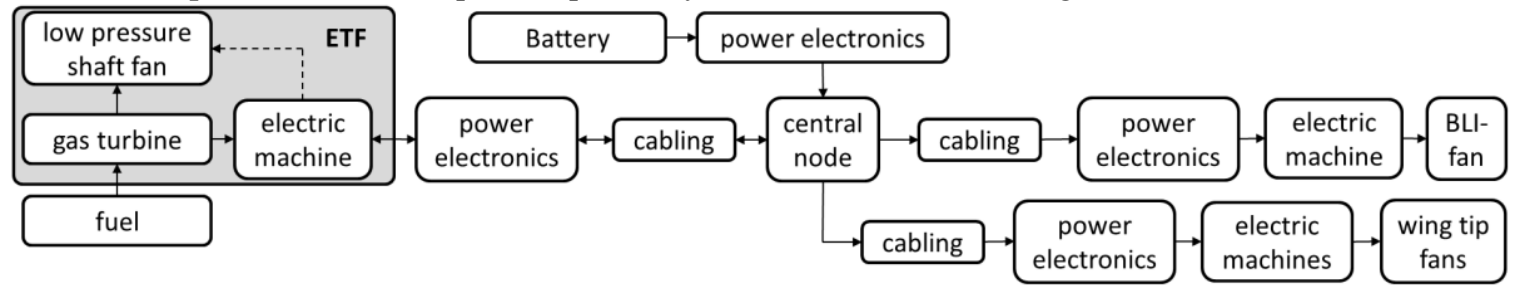

Fig. 19: Power flow of series/parallel partial hybrid powertrain for "BLI-WingFan" configuration

\section{Configurational impact of "T-tail" configuration}

A "T-tail" configuration is the baseline airframe layout for the "BLI-WingFan" configurations. Therefore, a Ttail configuration that is equipped with a conventional propulsion system (without BLI or tip fans) is analyzed in order to outline solely the impact of the configurational changes. For this purpose a design space survey is performed and the most promising T-tail configuration is compared to the advanced reference configuration in Fig. 20. According to the results, the integration of a T-tail leads to an improvement in the aerodynamic performance keeping the same MTOM. Corresponding, the block fuel consumption reduces by $2 \%$. This value is considered optimistic. Nevertheless, in the scope of these studies, the calculated value is used without modifications.

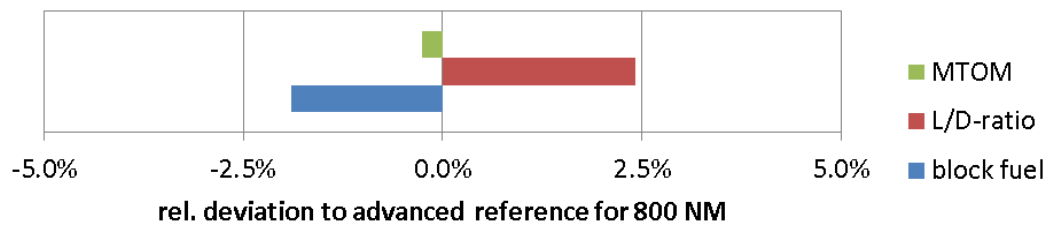

Fig. 20: Configurational impact of the T-tail configuration

\section{Design space exploration, "BLI-WingFan" configuration for $800 \mathrm{NM}$ and $13.6 \mathrm{t}$ of payload}

In order to evaluate the impact of the fans at the wing tips, studies with different degrees of contribution of tip fans are conducted. For each contribution fraction, the degree of hybridization and the wing aspect ratio are varied. Depending on the size of the tip fans, the volume coefficient of the VTP is reduced proportionally. In Fig. 21, the results related to the relative block fuel deviation compared to the reference configuration are shown. Each graph 
represents a certain contribution fraction of the wing tip fans to the yaw control: left: $0 \%$, middle: $25 \%$, right: $50 \%$. The wing span constraint of $36 \mathrm{~m}$ is marked by the red line.

Within the design space, the block fuel mass increases for a higher tip fan contribution fraction. According to the results, no benefit in utilizing the fans at the wing tips along with the reduced size of the VTP can be observed.


Fig. 21: Relative deviation in block fuel mass depending on the degree of hybridization, wing aspect ratio, and the contribution fraction of the wing tip fans to the yaw moment (design range: $800 \mathrm{NM}$, payload 13.6 $\mathrm{t}$ )

\section{Description of most promising "BLI-WingFan" concept for $800 \mathrm{NM}$ and $13.6 \mathrm{t}$ of payload}

According to the design space exploration, the most promising BLI-WingFan configuration incorporates no wing fans (contribution fraction of 0). This configuration is therefore only equipped with an electrically driven BLI-fan at the fuselage and a battery to improve the operating point of the gas turbines in cruise conditions. For further discussions this configuration is called the "BLI-ETF"-concept. The geometry of the corresponding configuration is shown in Fig. 22. The main data of the aircraft and the comparison to the advanced reference configuration for 800 NM are given in Table 7.

According to the studies, the most beneficial DOH is $10 \%$. Compared to the advanced reference configuration the block fuel mass and the block energy are reduced by $2 \%$. The MTOM is $3 \%$ higher and the mass of the electrical propulsion system including the cooling system and the battery is about $2 \mathrm{t}$.

Table 7: "BLI-ETF" configuration, key parameters

\begin{tabular}{|c|c|c|c|c|}
\hline Parameter & Unit & $\begin{array}{l}\text { Advanced reference } \\
\text { configuration for } 800 \mathrm{NM}\end{array}$ & $\begin{array}{l}\text { BLI-ETF } \\
\text { for } 800 \mathrm{NM}\end{array}$ & Deviation \\
\hline MTOM & {$[\mathrm{t}]$} & 61.1 & 62.8 & $2.9 \%$ \\
\hline OEM & {$[\mathrm{t}]$} & 38.6 & 40.5 & $4.9 \%$ \\
\hline wing reference area & {$\left[\mathrm{m}^{2}\right]$} & 97.1 & 99.9 & $2.9 \%$ \\
\hline wing aspect ratio & {$[-]$} & 13.3 & 13.0 & $-2.5 \%$ \\
\hline block fuel & {$[\mathrm{t}]$} & 3.23 & 3.16 & $-2.1 \%$ \\
\hline block energy & {$[\mathrm{GJ}]$} & 138.6 & 136.2 & $-1.8 \%$ \\
\hline battery mass & {$[\mathrm{t}]$} & 0.0 & 0.8 & 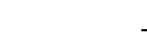 \\
\hline electric propulsion system & {$[\mathrm{t}]$} & 0.0 & 1.0 & - \\
\hline cooling system & {$[\mathrm{t}]$} & 0.0 & 0.2 & - \\
\hline $\mathrm{L} / \mathrm{D}$ cruise & {$[-]$} & 17.3 & 17.3 & $-0.2 \%$ \\
\hline
\end{tabular}




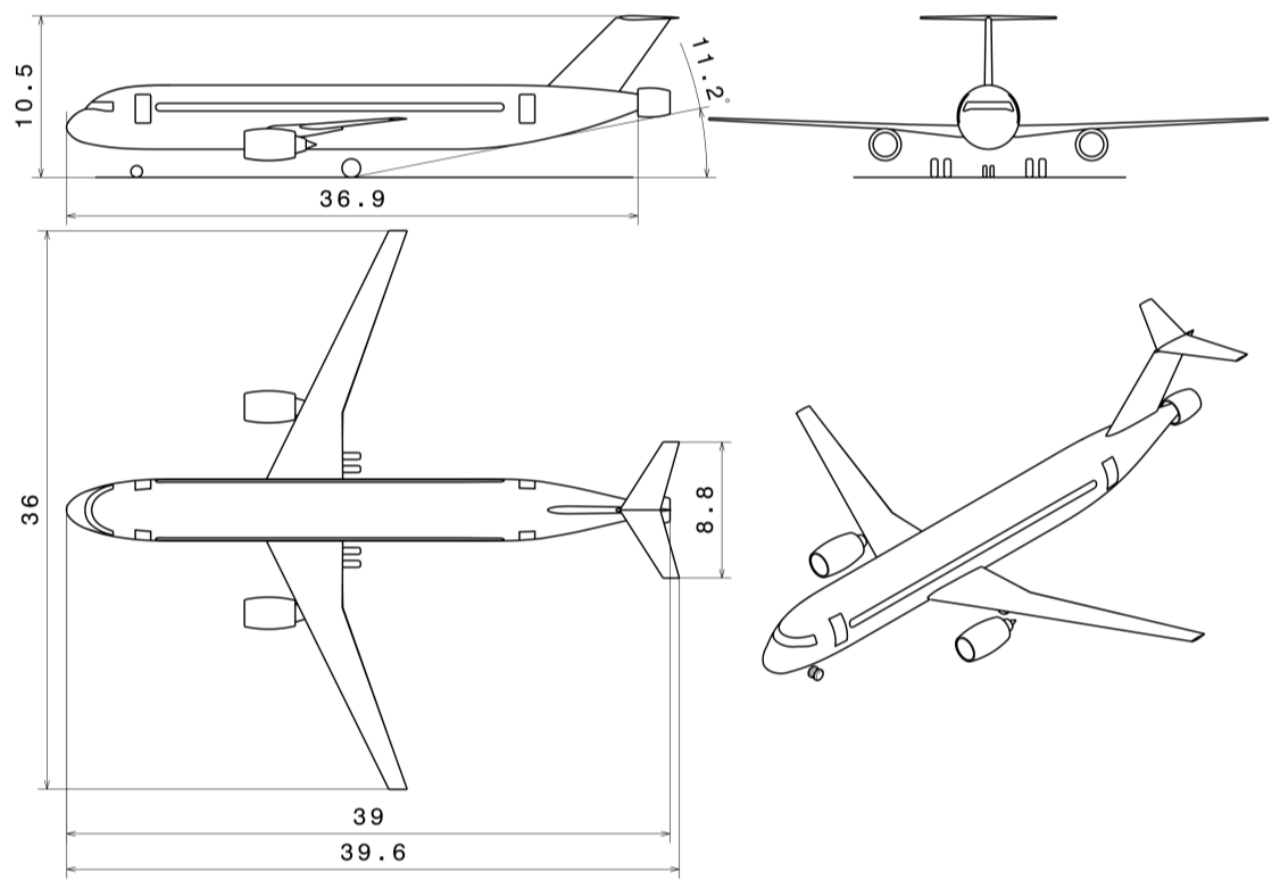

Fig. 22: Geometry of "BLI-ETF" configuration (800 NM, $13.6 \mathrm{t}$ of payload)

For the sake of consistency, the most efficient "BLI-WingFan" configuration that is equipped with fans at the wing tips is shown in Fig. 23. The aircraft data and the comparison to the advanced reference configuration for $800 \mathrm{NM}$ are summarized in Table 8. The contribution of the tip fans to the yaw moment for the take-off with OEI is $25 \%$. The most promising power based DOH results as $20 \%$. The MTOM is increased by $7.5 \%$ compared to the advanced reference configuration because of the additional powertrain components. Due to the wing span constraint, the aspect ratio is reduced by $6 \%$. The L/D-ratio improves slightly due to the reduced size of the VTP and comparably small tip fans. The block fuel is reduced by $1 \%$. The block energy is nearly the same as for the advanced reference configuration due to the high $\mathrm{DOH}$. The additional mass of the hybrid electric powertrain is $4 \mathrm{t}$, including the cooling system and the battery.

Table 8: "BLI-WingFan" configuration, key parameters

\begin{tabular}{llrrr}
\hline \hline & & $\begin{array}{l}\text { Advanced reference } \\
\text { Parameter }\end{array}$ & Unit & BLI-WingFan \\
configuration for 800NM & for 800NM & Deviation \\
\hline MTOM & {$[\mathrm{t}]$} & 61.1 & 65.7 & $7.5 \%$ \\
OEM & {$[\mathrm{t}]$} & 38.6 & 43.4 & $12.2 \%$ \\
wing reference area & {$\left[\mathrm{m}^{2}\right]$} & 97.1 & 104.4 & $7.5 \%$ \\
wing aspect ratio & {$[-]$} & 13.3 & 12.5 & $-6.3 \%$ \\
block fuel & {$[\mathrm{t}]$} & 3.23 & 3.19 & $-1.1 \%$ \\
block energy & {$[\mathrm{GJ}]$} & 138.6 & 138.0 & $-0.5 \%$ \\
battery mass & {$[\mathrm{t}]$} & 0.0 & 2.3 & - \\
electric propulsion system & {$[\mathrm{t}]$} & 0.0 & 1.4 & - \\
cooling system & {$[\mathrm{t}]$} & 0.0 & 0.3 & - \\
L/D cruise & {$[-]$} & 17.3 & 17.6 & $1.3 \%$ \\
\hline \hline
\end{tabular}






Fig. 23: Geometry of "BLI-WingFan" configuration

5. Design space exploration, "BLI-ETF" configuration for 2500 NM and $17 t$ of payload

As for the "Boosted Turbofan" configuration in section A, a design space survey is performed to evaluate the "BLI-ETF" configuration as the most promising "BLI-WingFan" concept at $2500 \mathrm{NM}$ and $17 \mathrm{t}$ of payload. The relative deviation in block fuel, block energy, and MTOM are shown in Fig. 25. The resulting reduction in block fuel mass is $3 \%$. The reduction in block energy is in the same order of magnitude. The MTOM is slightly increased. The most beneficial DOH is $10 \%$.
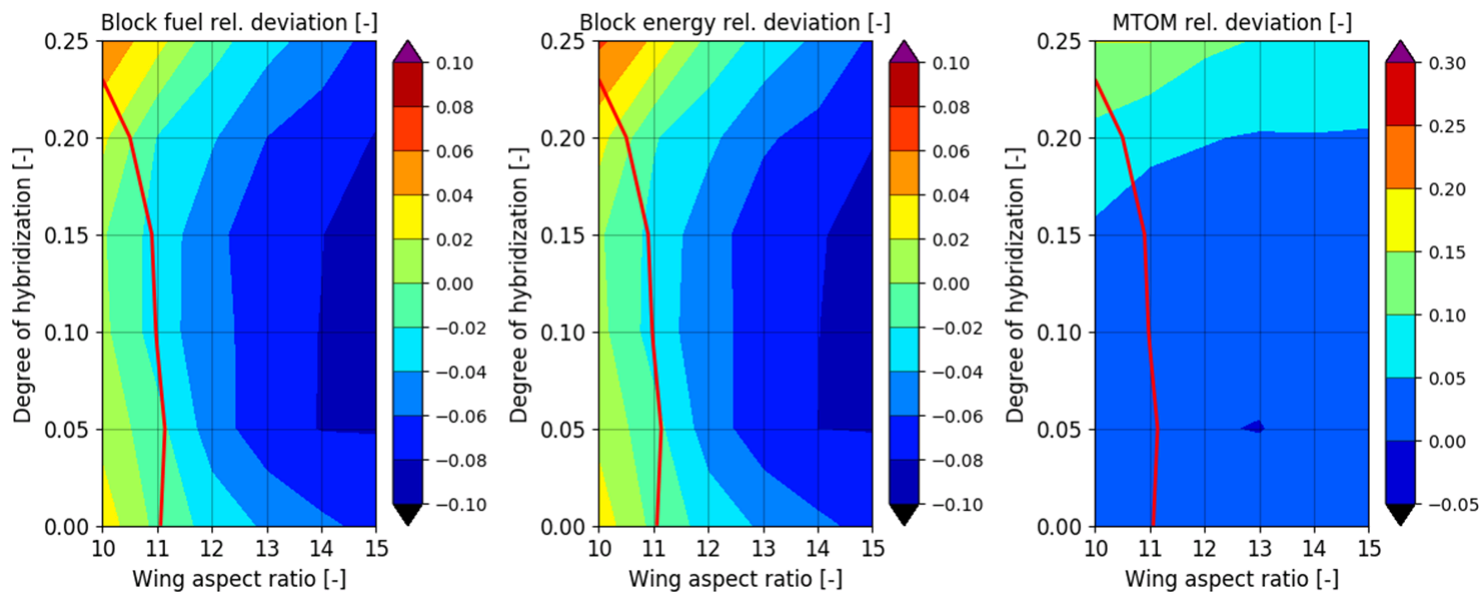

Fig. 24: Relative deviation in block fuel, block energy and MTOM for "BLI-ETF" configurations (design range: $2500 \mathrm{NM}$, payload $17 \mathrm{t}$ )

6. Impact of inflow distortion due to the location of the VTP

As described in section III.3, for the "BLI-WingFan" configuration the efficiency of the BLI-fan is reduced by $1.5 \%$. This correction factor is applied to the whole map and models the fan efficiency losses due to the non-uniform inflow caused by the VTP in front of the nacelle. In Fig. 25, the impact of this assumption on the block fuel mass is shown. The assumed loss of $1.5 \%$ leads to a relative increase in block fuel by $1.0 \%$. 


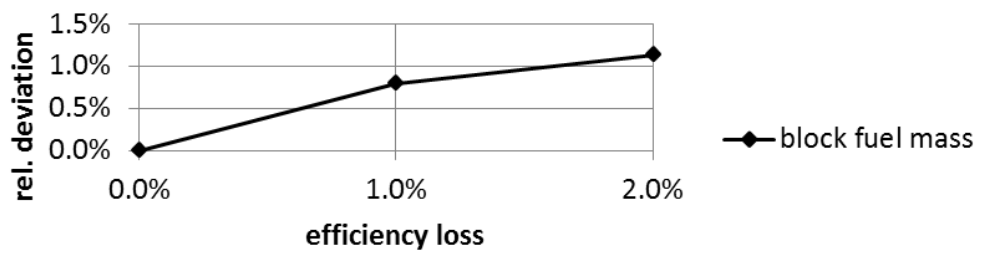

Fig. 25: Impact of efficiency reduction of the BLI-fan on block fuel mass at aircraft level

\section{Comparison of Configurations with Hybrid Electric Propulsion and Discussion of Results}

In this section, the most promising configurations designed for $800 \mathrm{NM}$ and $13.6 \mathrm{t}$ of payload are compared and the findings of the previous studies are discussed. The numbers mentioned in the discussion describe the impact of different effects at aircraft level.

\section{Comparison of configurations}

Fig. 26 shows the relative deviation in block fuel, block energy, masses, and the L/D-ration of the most promising HEP concepts related to the advanced reference configuration with a conventional propulsion. The "Boosted Turbofan" concept that benefits from the improved efficiency of the gas turbines during cruise shows a reduction in block fuel mass of about $2 \%$. Among the investigated HEP concepts, this configuration is related to the lowest uncertainties. The "BLI-ETF" configuration shows a similar potential as the "Boosted Turbofan" but at the same time results in a higher mass. The "BLI-WingFan" concept (PYC contribution factor: 25\%) offers the smallest benefit in terms of the fuel consumption and energy demand. At the same time it has the highest MTOM and OEM. The "BLI-Canard" configuration shows a benefit of $3 \%$ in terms of the block fuel mass. The MTOM is increased by $3 \%$ and the aerodynamic performance is improved by $2 \%$ compared to the advanced reference. However, this configuration bares the highest uncertainties.

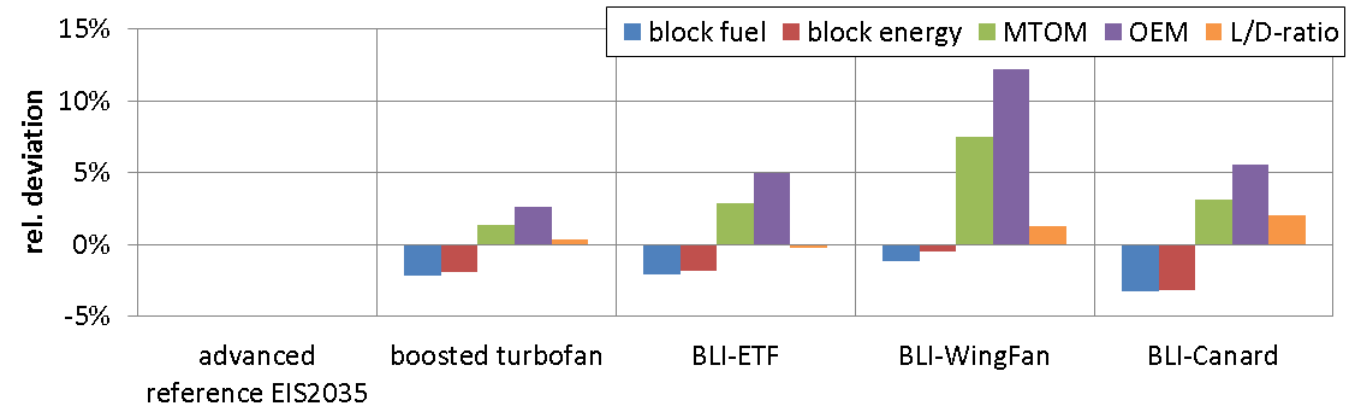

Fig. 26: Comparison of most promising HEP-configurations (design range: $800 \mathrm{NM}$ )

\section{Discussion of results}

The "Boosted Turbofan" configuration shows purely the impact of a parallel hybrid electric powertrain that improves the efficiency of the gas turbines at cruise conditions. The design space exploration shows that a low degree of hybridization of $10 \%$ is most beneficial. Due to the additional powertrain components, the MTOM and the OEM are increased by $1 \%-2 \%$. The total benefit in block fuel consumption is about $2 \%$ for the $800 \mathrm{NM}$ mission. This value is slightly higher for the $2500 \mathrm{NM}$ mission which can be explained by a longer cruise segment that allows the gas turbines to operate at higher efficiency over a larger period of the mission. The benefit is strongly influenced by the battery model that allows comparably high power densities combined with reduced energy densities.

The "BLI-Canard" configuration shows the impact of several combined effects. This airframe differs significantly from the reference aircraft. The corresponding impact is an increase in block fuel mass by $4 \%$, if a conventional propulsion system is applied and the length of the fuselage is kept unchanged. This value is comparably high and a more sophisticated optimization could improve the performance of this configuration further. Nevertheless, the relative deviation in performance due to the modifications enabled by the integration of a hybrid electric powertrain remains valid. The series/parallel partial hybrid powertrain improves the efficiency of gas turbines at cruise conditions as a parallel hybrid. The BLI-fan offers the benefit of a higher propulsive efficiency. At the same time, the hybrid electric powertrain and the airframe lead to an increase in mass. As the final result, the combined impact of those effects is a reduction in the block fuel consumption by $3 \%$.

The "BLI-ETF" configuration incorporates a modified tailplane and a BLI propulsor at the fuselage. In addition, the "BLI-WingFan" also features fans at the wing tips for powered yaw control. A T-tail configuration with a conventional propulsion leads to a reduction in block fuel mass by $2 \%$ compared to a conventional layout. This 
result is considered optimistic and should be checked during the subsequent work. According to the "Boosted Turbofan" studies, the improved sizing point of gas turbines provides a benefit of $2 \%$ at aircraft level. In total, this would lead to an improvement in performance by about $4 \%$ for a configuration with a parallel hybrid powertrain and a T-tail. The "BLI-ETF" configuration shows the combined impact of the T-tail configuration, the more efficient gas turbines, and the boundary layer ingestion. Since the cumulated impact is only about $2 \%$, it is concluded that the integration of the BLI-fan at the fuselage reduces the performance by approximately $2 \%$ at aircraft level. The study regarding the efficiency loss of the BLI-fan due to an inflow distortion reveals that the block fuel consumption can be reduced by $1 \%$ at aircraft level in case of a clean inflow, resulting in a total benefit of $3 \%$. The actual "BLIWingFan" configuration finally shows the impact of the powered yaw control availed by additional fans at the wing tips and the reduced size of the VTP. The total benefit in block fuel mass of $1 \%$ compared to the advanced reference configuration indicates a penalty of $1 \%$ due to the substitution of the VTP area by additional propulsors.

\section{Summary and Conclusion}

In this paper, the activities of the German Aerospace Center (DLR) related to the conceptual design of hybrid electric aircraft for a typical short range mission within the European project Clean Sky 2 are described. For the analyses, an overall aircraft sizing workflow based on low level physics based and semi-empirical methods is utilized. This workflow is used to calculate all configurations in order to assure consistent results for a ranking. A set of reference configurations is generated to evaluate the sizing workflow and to provide meaningful benchmark configurations with conventional propulsion at the same technology level as the investigated hybrid electric configurations. As the result, for a tube and wing configuration the block fuel mass is reduced by $27 \%$ between the technology levels for EIS1990 and EIS2035. The main drivers for this benefit are the advanced engine technology and the utilization of the CFRP for the wing. Further airframe technologies that are not directly related to HEP are not applied in order to outline the impact of the hybrid electric propulsion system.

Three hybrid electric configurations are investigated in the scope of this work. Design space studies are conducted to identify the most promising combinations of parameters as the degree of hybridization, the wing aspect ratio, the amount of powered yaw control, the length of the fuselage, the wing loading, and the efficiency loss due to the inflow distortion. A typical wing span constraint of $36 \mathrm{~m}$ is applied for the limitation of the design space. The most promising combinations of parameters for each configuration are identified and described in detail.

The analyses show that for the "Boosted Turbofan" configuration, a total benefit in block fuel and block energy is about $2 \%$ for the design ranges of $800 \mathrm{NM}$ and $2500 \mathrm{NM}$. The "BLI-Canard" configuration exhibits a reduction in block fuel mass of 3\% assuming a reduction in fuselage length by 5\% and the same high-lift capability as the reference configuration. The "BLI- WingFan" configuration shows a reduction in block fuel of $1 \%$. A "BLIWingFan" configuration without fans at wing tips, referred to as "BLI-ETF", shows a benefit of about $2 \%$ w.r.t. block fuel and block energy. For the majority of configurations, the DOH of $10 \%$ appears most promising. Solely for the "BLI-WingFan" configuration, the lowest block fuel consumption is at the DOH of $20 \%$. No benefits for higher DOH could be identified at the technology level assumed.

In order to evaluate the impact of the hybrid electric propulsion, a decomposition of the effects introduced by the configurational changes and the integration of the hybrid propulsion system is performed. The results show that in the scope of this work the improved sizing point of gas turbines due to hybridization leads to a reduction in block fuel by about $2 \%$. The integration of the BLI-fan at the fuselage appears disadvantageous but several underlying assumptions are considered conservative. The integration of additional propulsors solely for the powered yaw control along with a reduction of the VTP area leads also to an inferior performance. For this concept, further improvements are also conceivable.

\section{Outlook}

The presented work is focused on the design space exploration of different configurations. Based on these results, studies related to dedicated configurations can be conducted taking into account higher fidelity methods. The suggestions for the next steps, based on the lessons learned during these studies, are summarized in this section.

For all configurations, a more flexible tool for the optimization of the mission profile is required. During the mission, the operational strategy under consideration of different energy sources should be optimized. Also, the potential failure cases and the flexibility introduced by the hybrid electric distributed propulsion should be investigated in more detail. Further uncertainties in the presented studies are related to the mass of BLI-fans and the gas turbines. Especially the mass estimation for the fans with an unconventional design, as BLI-fans and wing tip fans, should be improved. Also, a wider range of thermodynamic models should be utilized for the sizing of the propulsion system in order to avoid excessive scaling factors. Also, a redesign of the gas turbines under 
consideration of the flexibility in operation due to HEP might reveal further potential benefits. Additional parameters for overall aircraft design as the integration of the landing gear should be taken into account in the optimization process.

The utilization of the boundary layer ingesting device at the fuselage requires a more detailed investigation. The operational strategy of the electrically powered propulsors in OEI case should be adapted considering the individual efficiencies. For instance, the BLI-fan could be supplied with its maximum power by battery during OEI. The fraction of the thrust and the amount of the ingested boundary layer should be introduced as parameters. Both affect the mass, the size, and the propulsive efficiency of the system. The ingestion of the whole boundary layer is not the optimum according to Seitz et al. in [25]. Further improvement in the performance of BLI-configurations can be achieved through a coupled aero-propulsive design as described by Gray et al. in [26]. This would also improve the level of fidelity of results. Furthermore, a detailed sizing of the wing-mounted ETF nacelles considering the integration of the additional electrical machines and the modified main fan diameters is required.

Considering the "BLI-Canard" configuration, a more detailed optimization of the airframe should be performed. Since the reduced length of the fuselage due to a BLI-propulsor is essential for the benefits obtained, this assumption should be investigated in detail. In terms of aerodynamics, the design of the lifting surfaces (induced drag and high lift), the stabilizers, and the shape of the rear section of the fuselage should be in focus. Regarding the mass, the penalties for the wing due to the large winglets, and for the fuselage due to the BLI-propulsor require further investigation. Also the layout of the cabin should be revised due to the unfavorable location of the lifting surfaces.

For the "BLI-WingFan" configuration, the dynamic behavior of the propulsors at the wing tips should be analyized in detail. At the same time, the impact of the reduced size of the VTP should be evaluated in terms of flight dynamics. The boundary layer ingesting fan located behind the VTP suffers from the distorted inflow pattern. Detailed investigations regarding the efficiency loss and the aerodynamic and structural design of a distortion tolerant fan are required. The utilization of the fans at the wing tips in cruise for increasing the overall bypass ratio should be accounted for. As for the "BLI-Canard" configuration, the structural mass impact of the propulsors at the fuselage and at the wing tips needs to be analyzed.

\section{Acknowledgments}

The project leading to this application has received funding from the Clean Sky 2 Joint Undertaking under the European Union's Horizon 2020 research and innovation program under grant agreement No [CS2-LPA-GAM2018-01]. The authors would like to thank the project partners from ONERA (Peter Schmollgruber, Sebastien Defoort), TU Delft (Maurice Hoogreef, Leo Veldhuis, Roelof Vos, Reynard de Vries) and NLR (Jos Vankan, Onno Bartels, Henk Jentink) for their contributions during the concept generation and the subsequent downselection process. The authors would also like to thank the industry partners AIRBUS (Lars Joergensen) and Rolls-Royce (David Debney, Andrew Smyth) for their interest in this topic and their guidance. Finally, the authors would like to thank Matthias Strack, and Gabriel Chiozzotto, former DLR, for their contribution to the work presented in this paper.

\section{References}

[1] European Commission. (2011). Flightpath 2050: Europe's Vision for Aviation.

[2] Hepperle, M., "Electric Flight - Potential and Limitations", NATO Science and Technology Organization, Lisbon, Portugal, 2012, ULR: https://elib.dlr.de/78726/, [retrieved 2018]

[3] Antcliff, K. R., Guynn, M. D., Marien, T. V., Wells, D. P., Schneider, S. J., \& Tong, M. T. "Mission Analysis and Aircraft Sizing of a Hybrid-Electric Regional Aircraft”, AIAA Paper 2016-1028, January 2016

[4] Stoll, A. M., Bevirt, J. B., Moore, M. D., Fredericks, W. J., \& Borer, N. K., "Drag Reduction Through Distributed Electric Propulsion". Aviation Technology, Integration, and Operations Conference, Atlanta, AIAA, 2014

[5] Strack, M.; Chiozzotto, G. P.; Iwanizki, M.; Plohr, M.; Kuhn, M., "Conceptual Design Assessment of Advanced Hybrid Electric Turboprop Aircraft Configurations”, AIAA 2017-3068, AIAA AVIATION Forum, Denver, 2017

[6] Antcliff, K. R., \& Capristan, F. M., "Conceptual Design of the Parallel Electric-Gas Architecture with Synergistic Utilization Scheme (PEGASUS) Concept", AIAA Paper 2017-4001, June 2017

[7] Welstead, J. R., \& Felder, J. L., "Conceptual Design of a Single-Aisle Turboelectric Commercial Transport with Fuselage Boundary Layer Ingestion”, 54th AIAA Aerospace Sciences Meeting, San Diego, California, USA, 2016

[8] Hoogreef, M. F., Vos, R., Vries, R. d., Brown, M. T., Veldhuis, L. L., "Conceptual Assessment of Hybrid Electric Aircraft with Distributed Propulsion and Boosted Turbofans", AIAA, 2019

[9] Schmollgruber, P., Atinault, O., Cafarelli, I., Döll, C., François, C., Hermetz, J., Liaboeuf, R., Paluch, B., Ridel, M., "Multidisciplinary Exploration of DRAGON: an ONERA Hybrid Electric Distributed Propulsion", AIAA 2019-1585, AIAA Scitech 2019 Forum, San Diego, 2019 
[10] Mistree, F., Lewis, K., \& Stonis, L., "Selection in the Conceptual Design of Aircraft", Atlanta, Georgia Institute of Technology, 1994

[11] ULR: http://rcenvironment.de/ [retrieved 2017]

[12] Raffaelli, L., Chung, J.-H., \& Popović, I., "Optimization of a High Bypass Ratio Turbofan Engine Using Energy Storage", Derby, UK: 2016

[13] Horstmann, K. "Ein Mehrfach-Traglinienverfahren und seine Verwendung für Entwurf und Nachrechnung nichtplanarer Fluegelanordnungen", DFVLR, Braunschweig, 1987

[14] ILR of RWTH-Aachen, "CERAS Central Reference Aircraft data System", URL: https://ceras.ilr.rwth-aachen.de/, [retrieved 2017]

[15] Raymer, D., "Aircraft Design, A Conceptual Approach”, American Institute of Aeronautics and Astronautics, 2006

[16] Liersch, C.M., Hepperle, M., "A distributed toolbox for multidisciplinary preliminary aircraft design", CEAS Aeronautical Journal, pp. 57-68, December 2011, ULR https://elib.dlr.de/74509/, [retrieved 2018]

[17] Nagel, B., Böhnke, D., Gollnick, V., Schmollgruber, P., Rizzi, A., Rocca, L., Alonso, J., "Communication in aircraft design: Can we establish a common language", 28th International Congress of The Aeronautical Sciences, Brisbane, 2012

[18] Hartmann, J., Pfeiffer, T., Breymann, B., Silberhorn, D., Moerland, E., Weiss, M., Nagel, B., "Collaborative Conceptual Design Of a Mid-Range Aircraft Under Consideration Of Advanced Methods For Technology Assessment", ICAS2018_0167, 2018

[19] Moerland, E., Pfeiffer, T., Boehnke, D., Jepsen, J., Freund, S., Liersch, C., Chiozzotto, G. P., Klein, C., Scherer, J., Hasan, Y. J., "On the Design of a Strut-Braced Wing Configuration in a Collaborative Design Environment", 18th AIAAnISSMO Multidisciplinary Analysis and Optimization Conference, 2017

[20] Chiozzotto, G. P., "Initial Weight Estimate of Advanced Transport Aircraft Concepts Considering Aeroelastic Effects", AIAA 2017-0009

[21] Torenbeek, E., "Synthesis of Subsonic Airplane Design", Delft University Press, Mijnbouwplein 11, 2628 RT Delft, Delft, Netherlands, 1982

[22] VAMPzero, ULR: https://www.dlr.de/lk/en/desktopdefault.aspx/tabid-8151/13975 read-35501/, [retrieved 2018]

[23] Smith Jr., L. H. "Wake ingestion propulsion benefit", Journal of Propulsion and Power, Vol. 9, 1993, pp. 74-82.

[24] Roskam, J., "Airplane Design Part VI: Preliminary Calculation of Aerodynamic, Thrust and Power Characteristics", Roskam Aviation and Engineering Corporation, Rt4, Box 274, Ottawa, Kansas, 1987

[25] Seitz, A., \& Gologan, C., "Parametric Design Studies for Propulsive Fuselage Aircraft Concepts", CEAS Aeronautical Journal, 6, 2015, pp. 69-82.

[26] Gray, J. S., Mader, C. A., Kenway, W. G., \& Martins, J. R., "Modeling Boundary Layer Ingestion Using a Coupled Aeropropulsive Analysis", Journal of Aircraft, Vol. 55, No. 3, May-June 2018, pp. 1191-1199. 


\section{- Acknowledgement}

This project has received funding from the Clean Sky 2 Joint Undertaking (JU) under grant agreement No 807097. The JU receives support from the European Union's Horizon 2020 research and innovation programme and the Clean Sky $2 \mathrm{JU}$ members other than the Union.

\section{- Disclaimer}

The results, opinions, conclusions, etc. presented in this work are those of the author(s) only and do not necessarily represent the position of the JU; the JU is not responsible for any use made of the information contained herein.
